Research Article

\title{
Dynamic Analysis of the Scraper Conveyor under Abnormal Operating Conditions Based on the Vibration and Speed Characteristics
}

\author{
Shoubo Jiang ${ }^{\mathbb{D}},{ }^{1}$ Weijian Ren, ${ }^{1}$ Qinghua Mao, ${ }^{2}$ Qingliang Zeng ${ }^{(\mathbb{D}},{ }^{1,3}$ Pengfei Yu, ${ }^{1,4}$ \\ Kuidong Gao, ${ }^{1}$ and Liang Wang ${ }^{1}{ }^{1}$ \\ ${ }^{1}$ College of Mechanical and Electronic Engineering, Shandong University of Science and Technology, Qingdao 266590, China \\ ${ }^{2}$ Shaanxi Key Laboratory of Mine Electromechanical Equipment Intelligent Monitoring, \\ Xi'an University of Science and Technology, Xi'an 710054, China \\ ${ }^{3}$ College of Information Science and Engineering, Shandong Normal University, Ji'nan 250358, China \\ ${ }^{4}$ Department of Mechanical and Electronic Engineering, Shandong Chemical Industry Vocational College, \\ Weifang 261000, China \\ Correspondence should be addressed to Liang Wang; skd995967@sdust.edu.cn
}

Received 19 August 2020; Revised 12 January 2021; Accepted 29 January 2021; Published 8 February 2021

Academic Editor: Fabio Minghini

Copyright (C) 2021 Shoubo Jiang et al. This is an open access article distributed under the Creative Commons Attribution License, which permits unrestricted use, distribution, and reproduction in any medium, provided the original work is properly cited.

\begin{abstract}
The scraper conveyor is the key coal transportation equipment on the coal mining face. The conveyor often encounters the influence of abnormal working conditions, such as stuck chains, broken chains, and impact loads, which have a great effect on the smooth operation of the scraper chain and seriously affect the safety of coal production. If the chain breaks during the test, the broken link may fly out and hurt the tester. The test risk of the scraper conveyor under abnormal working conditions is relatively large; hence, the test research is impossible to carry out. The combination of experiment and simulation is used to carry out the research. The dynamic characteristic test bed of the chain drive system is created to collect the speed of the sprocket and the acceleration of the scraper. The two groups of data are obtained by simulation, and the accuracy of the simulation is verified by comparing the test data with the simulation data. The dynamic characteristics of the chain drive system under abnormal working conditions are analyzed by simulation. Results show that the longitudinal velocity of the link dramatically changes, the contact force increases by 5.4 times, and the link vibrates under impact loads. When the chain is stuck, the speed of the running direction suddenly changes, and the chainring vibrates. The contact force between the chainrings increases by 7.2 times compared with the smooth operation. When the chain is broken, the acceleration in the running direction of the link dramatically changes. This study provides a basis and reference for the further optimization design of the chain drive system and detection of the abnormal working conditions.
\end{abstract}

\section{Introduction}

The longwall fully mechanized mining face is composed of hydraulic support, scraper conveyor, coal shearer, and other types of auxiliary equipment [1]. The scraper conveyor is the only coal transportation equipment [2]. This equipment is also the fulcrum of the coal mining machine's running track and hydraulic support [3]. The scraper conveyor is the core equipment of the coal mine fully mechanized mining equipment. The chain drive system is the core subsystem of the scraper conveyor [4], and its stable and reliable operation is of great significance to the safe production of coal.

The heavy scraper conveyors are used in the coal production in large mining height fully mechanized mining face. During the operation of the scraper conveyor, the scraper conveyor is often affected by the impact load due to the periodic impact of the ground pressure and the unstable load, and faults, such as stuck chains and broken chains, occur [5]. These abnormal conditions have a significant effect on the smooth operation of the chain drive system and 
the service life of the chainring and sprocket. The dynamic characteristics of the chain drive system under abnormal working conditions should be studied. Heavy scraper conveyors are increasingly widely used with the expansion of coal mining scale [6]. These conveyors have large volume and mass [7]. The cost of conducting the test is high, and the test risk coefficient is large. Various performance parameters of the scraper chain are difficult to directly measure [8]; thus, relevant experimental research is nonconducive to carry out. The mine working face has explosion-proof requirements for the equipment used; thus, the dynamic characteristic data of the scraper chain are impossible to collect in the production site. We must use a combination of test and simulation and multibody dynamic theory to carry out the research on the dynamic characteristics of the scraper conveyor chain transmission system under abnormal conditions on the basis of the vibration and speed characteristics. The optimal design of the scraper conveyor chain drive system and the detection of abnormal working conditions must be further studied, which is of great significance to the safe and efficient transportation of coal.

At present, researchers have conducted a substantial amount of research on the scraper conveyor. Wang et al. [9] studied the influence of chain speed, static friction coefficient, particle size, and laying angle on the transport efficiency of scraper conveyor by using the discrete element method. However, the influence of impact load caused by coal falling on the chain drive system of scraper conveyor was not considered when the discrete element software was used for simulation analysis. The kinematic characteristics of the chain drive system under impact load were unobtained. Jiang et al. [10] studied the contact problem of the chain drive system of the scraper conveyor by establishing the finite element model of the chain drive system on the basis of the meshing characteristics of the chain drive system. Accordingly, the stability of the scraper conveyor is improved. However, only the von Mises stress and contact pressure curves in different areas of chain wheel and chain link were studied. The reasons for the failure in different positions of the chain drive system are analyzed. The corresponding kinematics analysis was not conducted for the chain drive system. Wang et al. [11] proposed the speed planning strategy of the comprehensive coordination of the scraper conveyor and shearer on the basis of the load analysis of scraper conveyor. However, the speed planning strategy was formulated only in conjunction with the load change of the scraper conveyor. No further in-depth study of the working process was conducted under different loads of sprocket speed and chain speed changes. Zhang et al. [12] combined theoretical research, numerical simulation, and experimental analysis and created a finite element dynamic differential model to simulate three working conditions of scraper conveyor, including starting, braking, and restarting after braking. The result of the simulation analysis and experimental testing indicated that the dynamic characteristics under three working conditions were obtained. However, the common abnormal working conditions of the two chain transmission systems, the stuck chain and the broken chain, were not analyzed. Jiao et al. [13] used dynamic analytical software to simulate the various working conditions of the scraper conveyor chain transmission system and thus obtained the variation rules of torque, contact force, and scraper chain tension under various working conditions. However, the speed and acceleration of sprockets and scraper chains under abnormal working conditions were not analyzed. The simulation was not combined with the test to easily verify the accuracy of the data obtained by the simulation difficult to verify.

Yang et al. [14] used AMESim to create the finite element model of the scraper conveyor, measured the chain tension, speed, and other parameters and change the rules during the start-up process of the scraper conveyor. They also obtained the start-up characteristics of the scraper conveyor. Wang et al. [15] obtained the dynamic tension of the chain link of the heavy scraper conveyor by using the method of timevarying dynamic analysis. Xie et al. [16] obtained the vibration speed, acceleration, and tension of the scraper chain system by simulating the chain clamping condition of the scraper conveyor chain transmission system and carried out the test verification. Jiang et al. [17] used the rigid-flexible coupling method to conduct a dynamic simulation of the chain drive system under three working conditions of full load, half load, and no-load. They also obtained the vibration characteristics of the chain and the contact force between the chain wheel and the chain link and the contact force between the chain links. The above-mentioned research did not conduct a systematic study on the dynamic characteristics of the chain drive system under abnormal working conditions. The dynamic characteristics of the chain drive system under the conditions of chain stuck, chain break, and impact load were not systematically described.

Several scholars have carried out a substantial amount of research on the wear of the scraper conveyor. Xia et al. [18] used the Plackett-Burman design method to screen the main influencing factors of the chute wear of the scraper and established a regression equation to predict the amount of wear. $\mathrm{Li}$ et al. [19] used a reciprocating friction testing machine to study the friction and wear of the chute of scraper conveyor under different media. They also obtained the friction law and wear characteristics of lignite, coking coal, and anthracite on the chute of scraper conveyor. Xia et al. [20] used the discrete element method and wear model to track the position change of coal particles in the wear process and obtained the wear mechanism and wear law of chute. Li et al. [21] carried out the bionic design of the scraper conveyor chute on the basis of the nonsmooth wearresistant theory and analyzed the stress and deformation of the bionic scraper conveyor via ANSYS analysis, thereby providing a theoretical basis for the wear-resistant bionic design of the scraper conveyor. Xia et al. [22] established the interaction analytical model of the bulk coal scraper conveyor with discrete element method and predicted the wear situation of the scraper conveyor chute in the transportation process. They also obtained the law of wear degree of different positions of the scraper conveyor chute. Li et al. [23] designed and prepared a new Fe-Ni-based composite material for the scraper conveyor chute by the method of spark 
plasma sintering, studied its performance, and summarized the wear mechanism.

The above research results are mainly aimed at the wear mechanism and wear characteristics of the scraper conveyor. In recent years, a systematic study on the dynamic characteristics of the chain drive system under abnormal operating conditions is scarce. In the actual work of the scraper conveyor, the abnormal working conditions of impact load, stuck chain, and broken chain are related to the safe operation of the scraper conveyor. These conditions affect the safety production of the whole coal mine. The dynamic characteristics should be systematically studied, and relevant conclusions should be drawn. This work studies the dynamic characteristics of the chain drive system under abnormal working conditions on the basis of the theory of multibody dynamics. The design of the chain drive system of the scraper conveyor should be further optimized, and the abnormal working conditions should be prevented. The occurrence of chain stuck and break should be prevented, and the stable operation of the chain drive system under the impact load should be ensured.

\section{Methods}

2.1. Overall Plan of the Research Program. Experiments on scraper conveyors under real working conditions are usually difficult. On one hand, the dynamic data of scraper conveyor chain drive system are difficult to collect in the production site and analyzed due to the high requirements of explosion-proof equipment in a fully mechanized mining face. The abnormal working conditions selected in this study include chain clamping, chain breaking, and impact load. The risk factor and operation difficulty of the test are relatively large. Considering the safety problem, the test cannot be used to study the chain clamping and chainbreaking conditions. The data, such as the contact force between links, are difficult to collect. On the other hand, although the length of a heavy-duty scraper conveyor exceeds 300 meters, usually with 2,3 , or more motors and 2 chains, experimenting on such a long and heavy scraper conveyor is very costly both in terms of space, time, electricity, funds, and labor.

Considering the above constraints, we build a test bed of shortened scraper conveyor with a single motor and chain to collect the typical data, such as speed and acceleration, and compare the collected data with the simulation data to verify the reliability of the simulation. The simulation method is used to study the dynamics of other abnormal working conditions. The typical vibration and velocity characteristic data of speed, acceleration, sprocket speed, and contact force between chain links under three abnormal working conditions, namely, stuck chain, broken chain, and impact load, are obtained by using ADAMS on the basis of the theory of multibody dynamics. The dynamic characteristics of the scraper conveyor under abnormal working conditions are summarized on the basis of the data. The working conditions studied are all abnormal conditions, and the test bed is only used to verify the reliability of the simulation by using the collected driven sprocket speed, so the shortening of the length of the test bed and the setting mode of the simulation drive will not affect the results.

\subsection{Dynamic Characteristic Test of the Chain Drive System}

2.2.1. Construction of the Test Bench. This study takes SGD320/17b scraper conveyor as the prototype. The dynamic characteristics of the test bed are then established. The size of the scraper conveyor is moderate, which is convenient to create the test bed and carry out related research. The actual installation length of the built-in scraper conveyor dynamic test bed is $12 \mathrm{~m}$, which can measure the data of the head and tail sprocket speed, scraper running attitude, and acceleration. The specific technical parameters of the test bed are shown in Table 1.

The rotational speed of the chain wheel at the head and tail of the machine is measured by laser pulse measurement. The pulse frequency of the reflected pulse of the reflector is collected with the laser transmitter. The fixed position of the reflector on the rear chain axle is shown in Figure 1(a). The reflectors are evenly distributed along the chain wheel axle circumference of $60^{\circ}$ to ensure the measurement accuracy. Data acquisition is carried out by using Donghua DHDAS dynamic signal acquisition and analytical system software. The acceleration data of scraper running are measured with a BWT901CL charging Bluetooth attitude transducer and used with a USB-HID Bluetooth receiver and host computer software MiniIMU. The installation location of the charging Bluetooth sensor is shown in Figure 1(b). Such a location is fixed above the scraper by sticking. Thus, only the running acceleration of the tension side of the scraper chain is measured.

2.2.2. Test Data Acquisition. The QBN9000-30 high-performance universal vector inverter is used in the test bench to control the motor speed. The frequency of the frequency converter used in the test is $20 \mathrm{~Hz}$. At this time, the theoretical speed of the head sprocket is $23.57 \mathrm{rpm}$, and the running speed of the scraper chain is approximately $2357 \mathrm{~mm} / \mathrm{s}$. The speed and acceleration acquisitions are simultaneously carried out with two computers. The speed signal acquisition interface is shown in Figure 2(a), and the acceleration signal acquisition interface is shown in Figure 2(b).

\subsection{Dynamic Simulation of the Chain Drive System}

\subsubsection{Establishment of the Simulation Model for the Chain} Drive System. In this study, it is not necessary to analyze the scraper conveyor as a whole but only focus on the dynamic characteristics of the link where the fault occurs and the actual chain drive system of the scraper conveyor is huge. When ADAMS is used to model and simulate the chain drive system, the model needs to be simplified. The simplified chain drive model established in ADAMS is shown in Figure 3 by using Pro/E to model the chain drive system, with 64 chain links and eight scrapers. 
TABle 1: Technical parameters of the test bench.

\begin{tabular}{lc}
\hline SGD320/17B & $\begin{array}{c}\text { Technical } \\
\text { parameter }\end{array}$ \\
\hline Rated operating voltage $(\mathrm{V})$ & 380 \\
Rated power of motor $(\mathrm{kW})$ & 18.5 \\
Rated speed of motor $(\mathrm{rpm})$ & 1470 \\
Transmission ratio of the reducer & 24.95 \\
Working length of scraper $(\mathrm{m})$ & 12 \\
Scraper conveyor size $($ length $\times$ width $\times$ height, & $600 \times 320 \times 156$ \\
mm) & $\Phi 14 \times 50$ \\
Chain specification &
\end{tabular}

This study defines the relevant constraints and boundary conditions in ADAMS (Figure 3). The chain wheel is constrained by a rotating pair, and a solid contact relationship is established between the sprocket and the flat ring. The scraper is directly fixed with the installation flat ring through fixed constraints. The solid contact relationship is established between the flat and the vertical ring and between the scraper and the equivalent scraper conveyor chute. A total of 208 contact pairs are established in the model.

For the scraper conveyor of the test bench, there is additional external resistance on the test bench. The resistance comes from two aspects: on one hand, there is resistance between the return drum and the test stand. On the other hand, the chain is wound on the sprocket, is fixed with the scraper, and runs in the middle chute. In coal conveying conditions, these coupling factors will also produce a lot of resistance, so for the return drum, there is also resistance. To simulate this situation, the speed boundary condition is applied to the driving sprocket, and the resistance torque is applied to the driven sprocket to simulate the load resistance in the actual working condition. The negative $Y$ direction defines the gravity acceleration and the scraper and chain contact with the middle trough plate under the action of gravity.

2.3.2. Analysis and Calculation of the Simulation Parameters. The simulation model of the chain drive system has many contacts. The contact parameters must be calculated to obtain reasonable simulation results.

The penetration depth is substituted into the contact force calculation equation to calculate the contact force.

$$
F=K^{*} d^{n},
$$

where $F$ is the contact force, $K$ is the stiffness of the material, $n$ is the force index, and $d$ is the penetration depth.

The contact stiffness was calculated by Hertz's theory.

$$
\left\{\begin{array}{l}
K=\frac{4}{3} R^{\prime 1 / 2} E^{\prime}, \\
\frac{1}{R^{\prime}}=\frac{1}{R_{1}}+\frac{1}{R_{2}}, \\
\frac{1}{E^{\prime}}=\frac{1-V_{1}^{2}}{E_{1}}+\frac{1-V_{2}^{2}}{E_{2}},
\end{array}\right.
$$

where $K$ is the contact stiffness of the material; $R_{1}$ and $R_{2}$ are the radius of curvature at the contact point and the material in contact, respectively; $E_{1}$ and $E_{2}$ are the elastic moduli of the materials in contact with each other; and $V_{1}$ and $V_{2}$ are Poisson's ratios of materials in contact with each other.

In the contact process, the magnitude of contact damping changes with the modification of the penetration depth. The real-time damping coefficient is calculated according to equation (3).

$$
C^{\prime}=\operatorname{step}(x, 0,0, \delta, C)= \begin{cases}0, & x \leq 0, \\ C\left(\frac{x}{\delta}\right)^{2}\left(3-2\left(\frac{x}{\delta}\right)\right), & 0<x<\delta, \\ C_{\max }, & x \geq \delta,\end{cases}
$$

where $C^{\prime}$ is the real-time damping coefficient of the contact process, $C_{\max }$ is the maximum damping coefficient, $x$ is the real-time penetration depth in the contact process, and $\delta$ is the maximum penetration depth.

The theoretical value of the maximum damping coefficient can be determined by equation (4).

$$
C=\frac{3 K\left(1-\varepsilon^{2}\right)}{4 u} \delta^{e},
$$

where $u$ is the relative velocity of two objects at the point of contact, $\varepsilon$ is the collision recovery coefficient of the contact, and $e$ is the nonlinear coefficient of the contact force.

After theoretical calculation and simulation, because the steel is chosen as the material in the simulation, the theoretical calculation value of the contact parameters between the chain link and the middle groove of the chain link is the same. The contact parameters $K=120000 \mathrm{~N} / \mathrm{mm}$, $C=500 \mathrm{~N} \cdot \mathrm{s} / \mathrm{mm}$, maximum contact depth $d=0.01 \mathrm{~mm}$, contact force nonlinear index $e=2.2$, static friction coefficient $\mu s=0.3$, and dynamic friction coefficient $\mu d=0.1$.

Under real loading process, the value of the rotational speed of the drum fluctuates with various loads. Simulation of fluctuating load is relatively difficult because it is impossible to accurately obtain the load spectrum under real conditions. In the simulation of this manuscript, although we have applied the start and deceleration phases, the focus is on the impact characteristics and the stuck and broken chains under stable operating conditions. Therefore, we set a constant speed during working conditions. The chain drive system starts from $0 \mathrm{~s}$ to $0.5 \mathrm{~s}$, and the chain speed increases from $0 \mathrm{~mm} / \mathrm{s}$ to $800 \mathrm{~mm} / \mathrm{s}$. The process from $0.5 \mathrm{~s}$ to $4.5 \mathrm{~s}$ is a stable operating stage, and the chain speed is stable at $800 \mathrm{~mm} / \mathrm{s}$. The process from $4.5 \mathrm{~s}$ to $5 \mathrm{~s}$ is a deceleration braking process, and the chain speed is gradually reduced from $800 \mathrm{~mm} / \mathrm{s}$ to $500 \mathrm{~mm} / \mathrm{s}$.

The step function is used to represent the angular velocity change of the driving sprocket, and the set step function is as follows: 


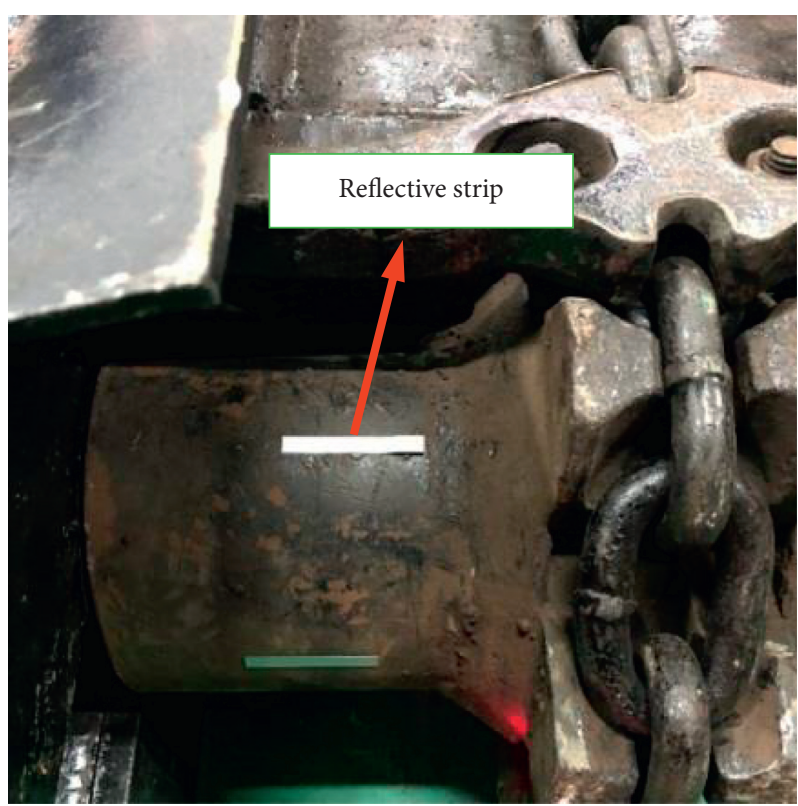

(a)

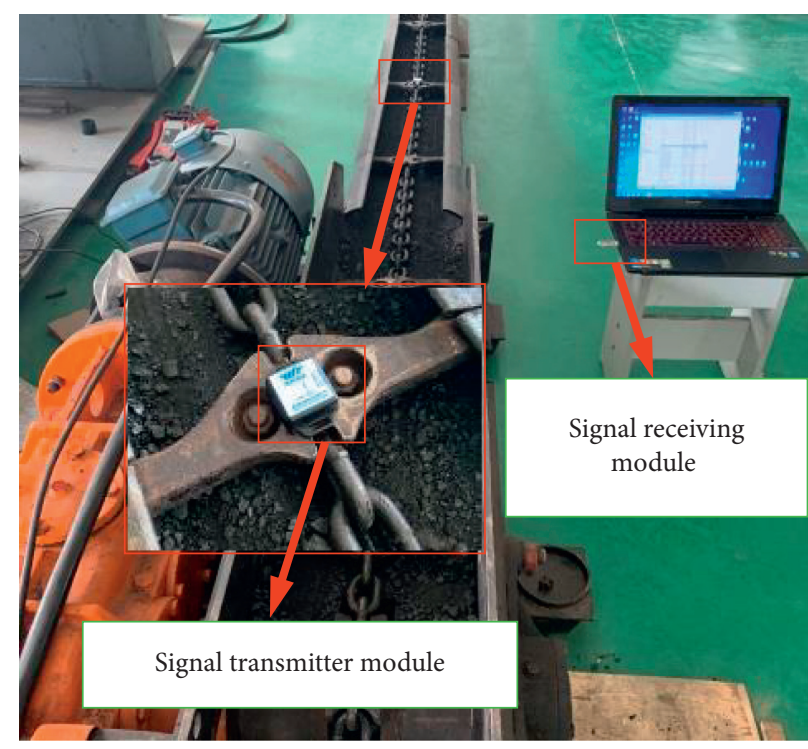

(b)

FIgURE 1: Sensor installation position. (a) Installation of the laser reflector. (b) Bwt901cl Bluetooth sensor installation.

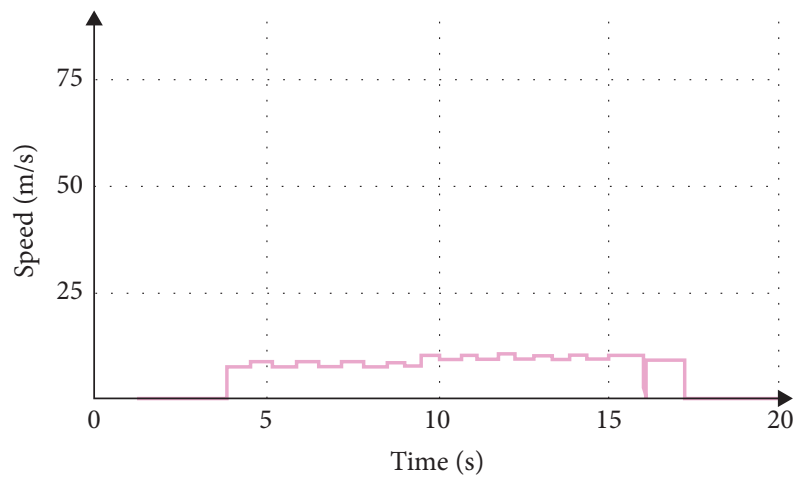

(a)

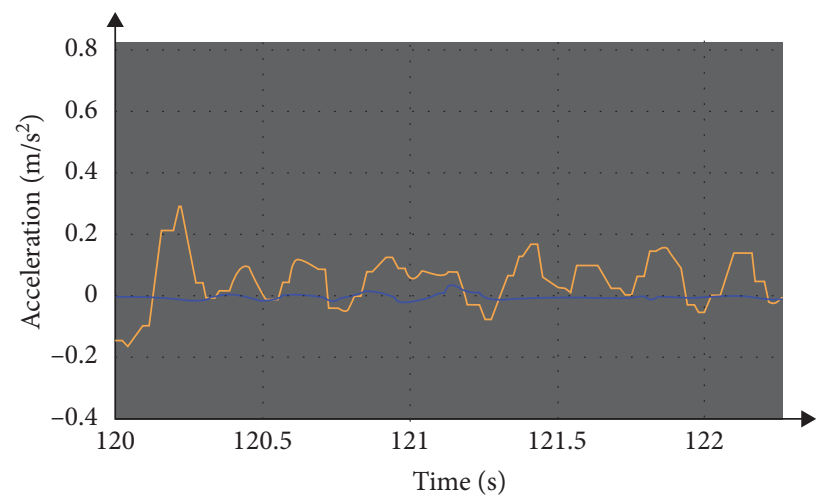

(b)

FIGURE 2: Signal acquisition software interface. (a) Speed signal acquisition. (b) Acceleration signal acquisition.

step (time, $0,0 d, 0.5,141.7 d)+\operatorname{step}($ time $, 4.5,0,5,-141.7 d)$.

When smoothly running, the torque at the driven sprocket is approximately $50 \mathrm{kN}$, which is also applied by the step function. The set step function is as follows:

step (time, 0, 0, 0.5, -1.6175e7) + step (time, 4.5, 0, 5, 1.6175e7).

The simulation time is set to $5 \mathrm{~s}$, the simulation steps are set to 5000 , and the interactive simulation is selected.

2.4. Comparison of Test and Simulation Data. After several groups of repeated tests, the speed change curves of the head and tail chain wheels are obtained (Figure 4(a)). The speed curve obtained by simulation in ADAMS is shown in Figure 4(b). The change trend of the simulation and test curves is roughly the same, and the influence of the polygon effect on speed can be observed. The speed fluctuations are approximately $11.14 \%$ and $4.45 \%$ in the text and simulation, respectively. In the simulation model, the head sprocket Sprocket1 sets the driving speed. Thus, Sprocket1 reflects the influence of the polygon effect on its speed. Because the comparison between the test data and the simulation data is mainly based on the data of stable operation stage to verify the accuracy of the simulation, so the test data only selects the former $4 \mathrm{~s}$.

When the frequency converter is set at $20 \mathrm{~Hz}$, the theoretical, experimental, and simulation results of the average speed of the sprocket are shown in Table 2. A slight difference can be observed among the simulation, test data, and theoretical calculation value. The simulation result is in line with the actual working conditions, and the credibility is high.

The test acceleration curve of the scraper is shown in Figure 5(a). The acceleration curve obtained by simulation in ADAMS is shown in Figure 5(b). The $X$ direction in the 


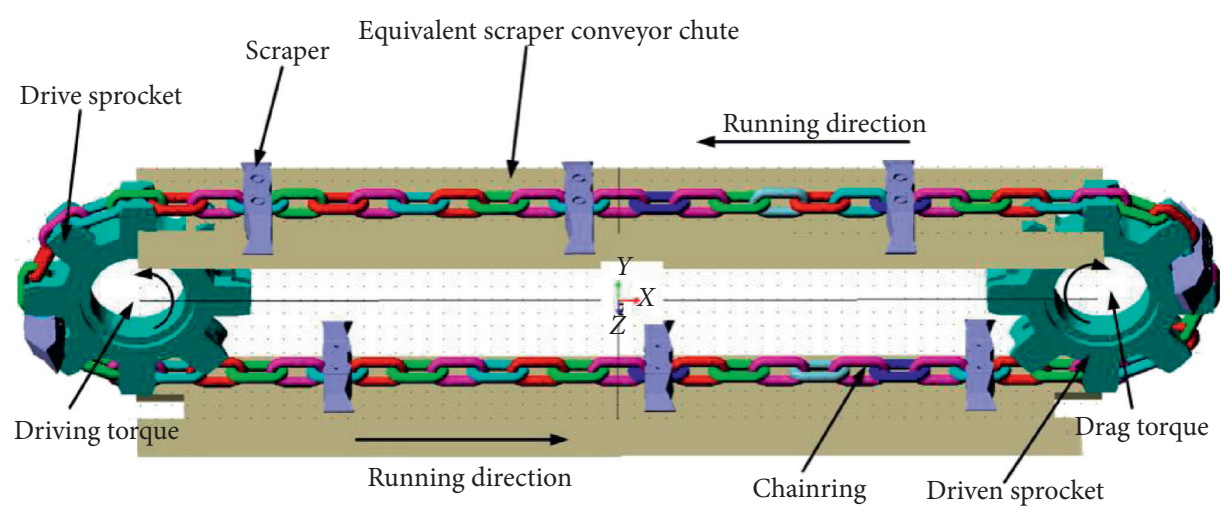

FIGURE 3: Simplified chain transmission system model.

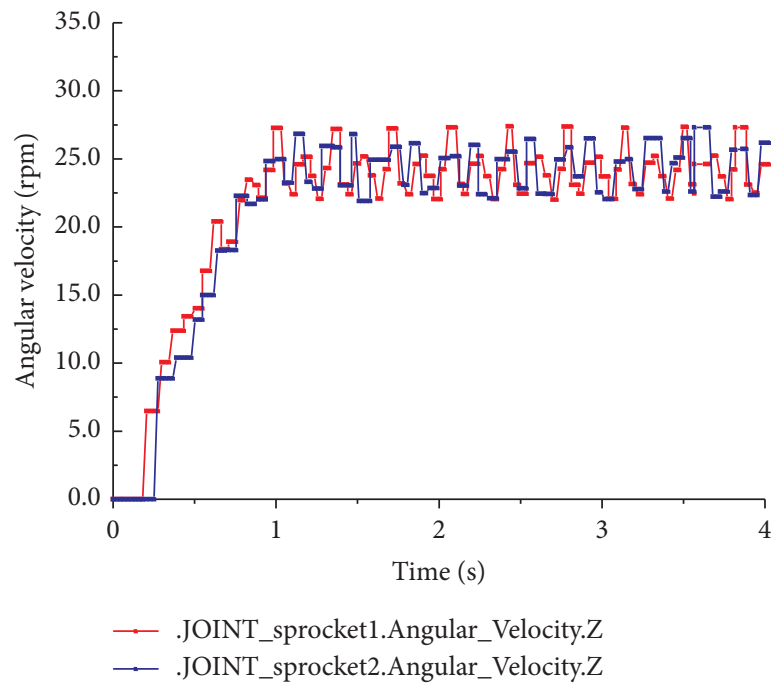

(a)

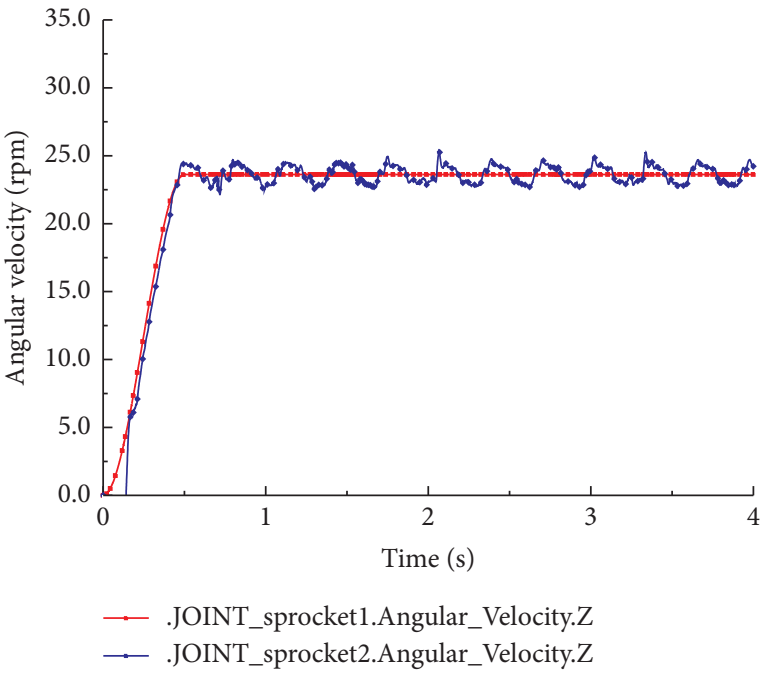

(b)

Figure 4: Sprocket rotational speed comparison. (a) Experimental data. (b) Simulation data.

TABle 2: Comparison of the test and simulation results.

\begin{tabular}{lcccc}
\hline Theoretical calculation & \multicolumn{2}{c}{ Test result } & \multicolumn{2}{c}{ Simulation result } \\
\hline Average rotating & Average rotating & Difference from & Average rotating & Difference from \\
velocity & velocity & theory & velocity $(0.5 \mathrm{~s}-4 \mathrm{~s})$ & theory \\
$23.57 \mathrm{rpm}$ & $24.15 \mathrm{rpm}$ & $2.46 \%$ & $23.62 \mathrm{rpm}$ & $0.21 \%$ \\
\hline
\end{tabular}

figure indicates the running direction of the scraper, and $Z$ represents the direction perpendicular to the bottom plate of the scraper conveyor chute. The comparison result between the simulation data and the test result curve demonstrates that the simulation results greatly fluctuate. The acceleration in the $X$ direction significantly fluctuates before $0.5 \mathrm{~s}$ due to the contact instability of the simulation model initial state. The curve is stable, basically between $-1000 \mathrm{~mm} / \mathrm{s}^{2}$ and $800 \mathrm{~mm} / \mathrm{s}^{2}$. The test curve is generally stable, and the acceleration fluctuation is small, which is basically stable between $-260 \mathrm{~mm} / \mathrm{s}^{2}$ and $250 \mathrm{~mm} / \mathrm{s}^{2}$.

The comparison result of the test and simulation data indicated that the simulation data of $X$ direction acceleration increases by $346.15 \%$ and the simulation data of $Y$ direction acceleration increases by $432.5 \%$. This is mainly because the contact parameters set in the simulation can not fully reflect the real contact situation. The change trend of the simulation and test results is basically consistent. The simulation results are consistent with the test data to a certain extent and have high reliability.

\section{Results and Discussion}

3.1. Impact Load Condition. The impact load condition is simulated by ADAMS. The method is to apply a vertical downward ( $Y$ direction) concentrated force load on the scraper near the driven sprocket side (Figure 6).

The step function is used to simulate the concentrated force load because the impact load is difficult to determine under actual working conditions. The loading time is 


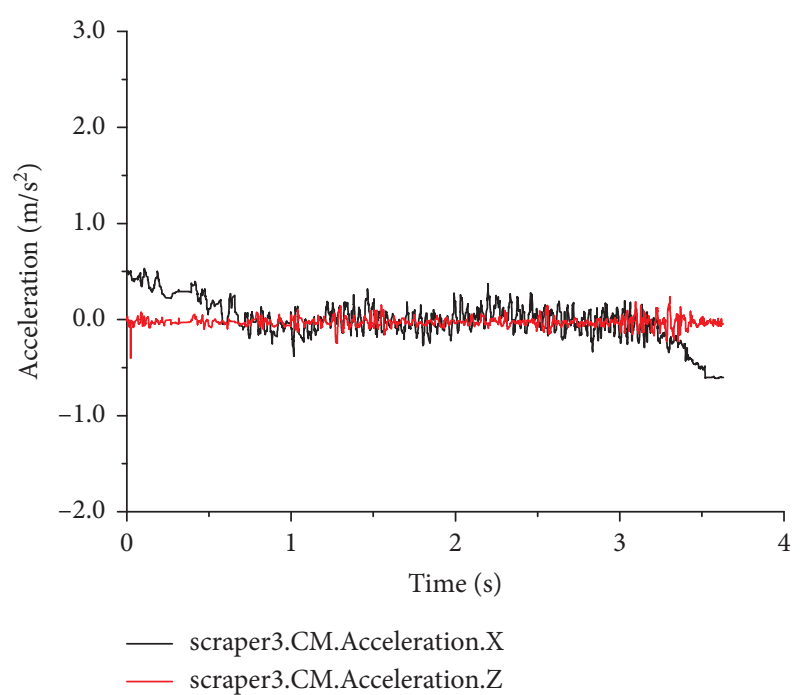

(a)

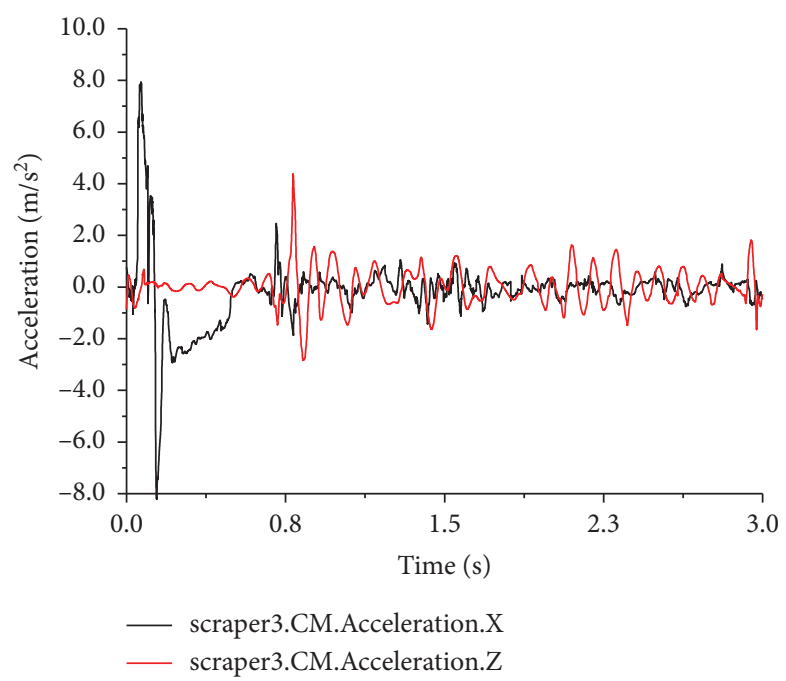

(b)

FIgURE 5: Scraper acceleration comparison. (a) Experimental data. (b) Simulation data.

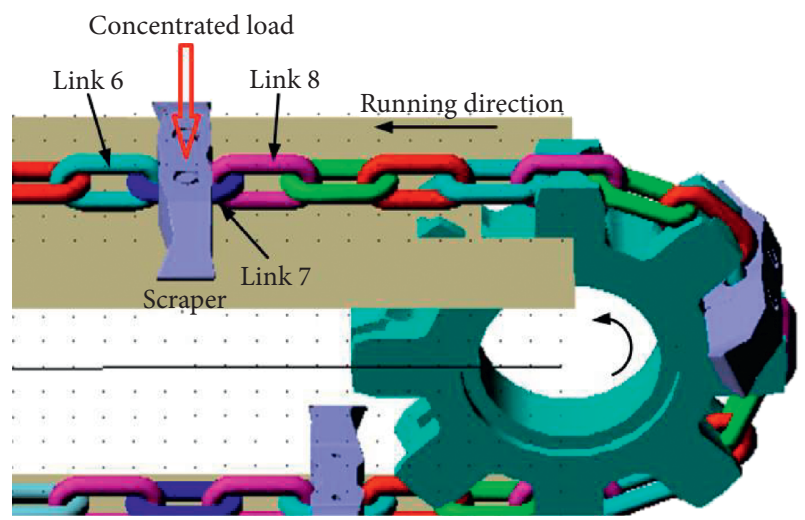

FIgURE 6: Impact load operating mode simulation.

$0.55 \mathrm{~s}-0.6 \mathrm{~s}$; that is, the concentrated force increases to $2 \cdot 10^{+6} \mathrm{~N}$ within $0.05 \mathrm{~s}$. Large friction exists between the scraper and the middle groove, and the concentrated force load is removed within $0.6-0.8 \mathrm{~s}$. The speed change curve of link 6 on the front side of the impact load of the chain drive system is shown in Figure 7. The acceleration change curve of link 6 is shown in Figure 8 .

Figure 7 demonstrates that the longitudinal speed of the chainring drastically changes when the chain drive system is subjected to an impact load. The $Y$ direction speed can reach up to $4340 \mathrm{~mm} / \mathrm{s}$, and a large speed fluctuation can be observed in the direction of motion. The speed amplitude change curve demonstrates that the speed of the chain link violently fluctuates. The speed reaches a maximum of $4720 \mathrm{~mm} / \mathrm{s}$ at $0.622 \mathrm{~s}$, thereby indicating that the chainring is trembling back and forth at this time. This phenomenon is related to the friction between the scraper and the middle groove under the impact load. When the impact load is removed, the link returns to normal operating speed.

The change curve of the chain link acceleration in Figure 8 demonstrates the change trend of acceleration in the $X$ direction, and that in the $Y$ direction is basically the same; however, the acceleration in the $Y$ direction is larger, which is approximately two times that in the $X$ direction. The maximum acceleration amplitude can reach $1.23 \cdot 10^{7} \mathrm{~mm} / \mathrm{s}^{2}$, thereby indicating that the link is greatly impacted. The change curve of the contact force between links 5 and 6 is obtained to study the stress of the link at this time (Figure 9).

Figure 9 shows that the indirect contact force of the chain link sharply increases under the impact load condition. The change is obvious in the running direction $(X$ direction). The change curve of the contact force demonstrates that the indirect contact force of the chain link is approximately $5 e 4 n$ when it smoothly runs. Under the impact load, the indirect contact force of the chain link instantaneously increases up to $2.7 \cdot 10^{5} \mathrm{~N}$, which is 5.4 times higher than that of the smooth operation. This finding shows that the chain drive system will be greatly impacted under the impact load condition.

Under the impact load condition, the increase of friction force will also have a certain impact on the running speed of the chain drive system. The variation curve of the sprocket speed is shown in Figure 10.

Because the main content of this study is the dynamic characteristics of the scraper chain in various abnormal conditions and the driving mode of the driving sprocket has little effect on the vibration of the scraper chain, so setting the driving sprocket to rotate at constant speed can simplify the complexity of the simulation model and improve the simulation speed. Figure 10 shows that the driving sprocket smoothly operates according to the given boundary conditions of $141.7^{\circ} / \mathrm{s}$. Under the impact load condition, the speed of the driven side sprocket significantly fluctuates (ranging from $-121.8^{\circ} / \mathrm{s}$ to $410.2^{\circ} / \mathrm{s}$ ). When the speed fluctuation is large, the operating stability of the chain drive system will be affected. Consequently, the meshing contact force of the sprocket assembly changes, thereby affecting the service life of the sprocket assembly. 


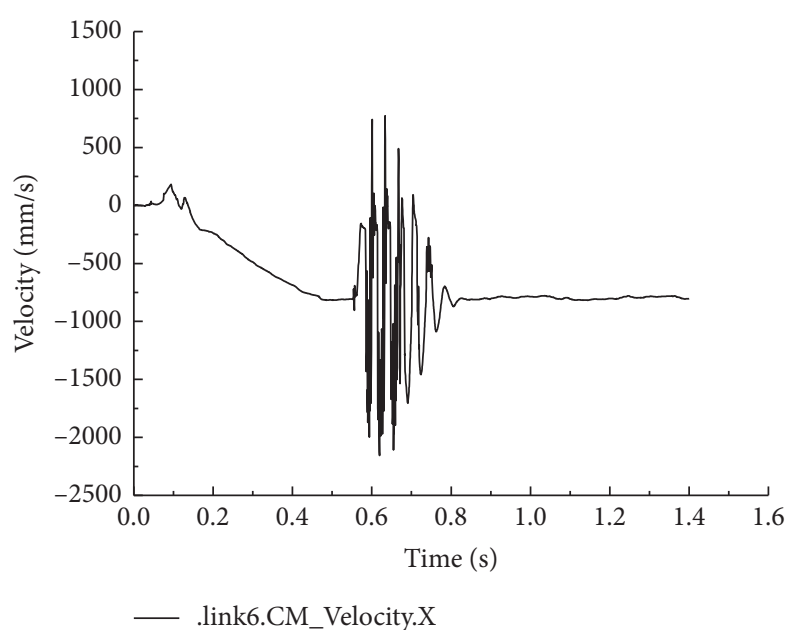

(a)

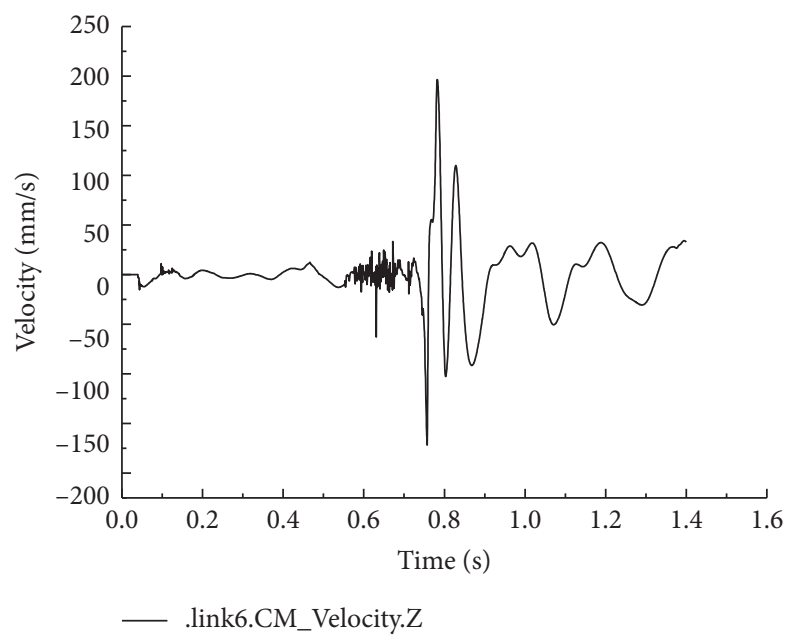

(c)

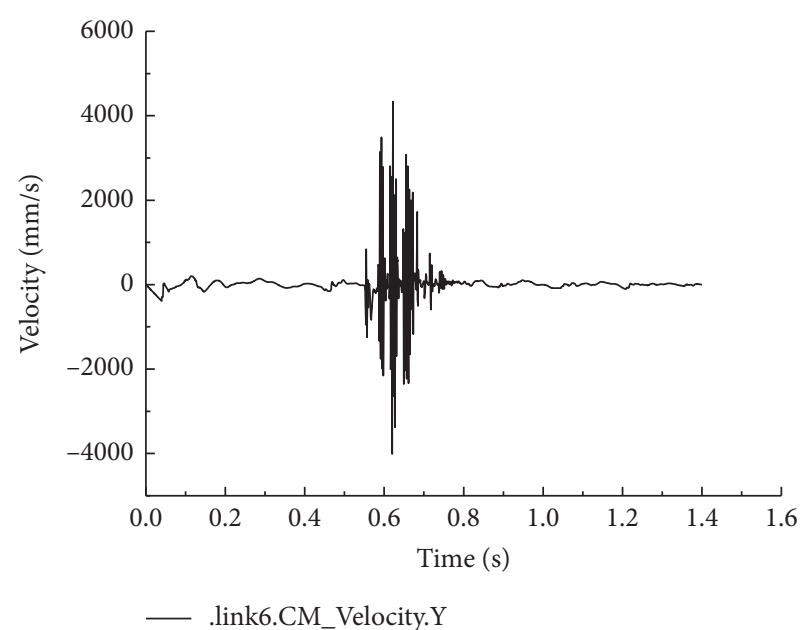

(b)

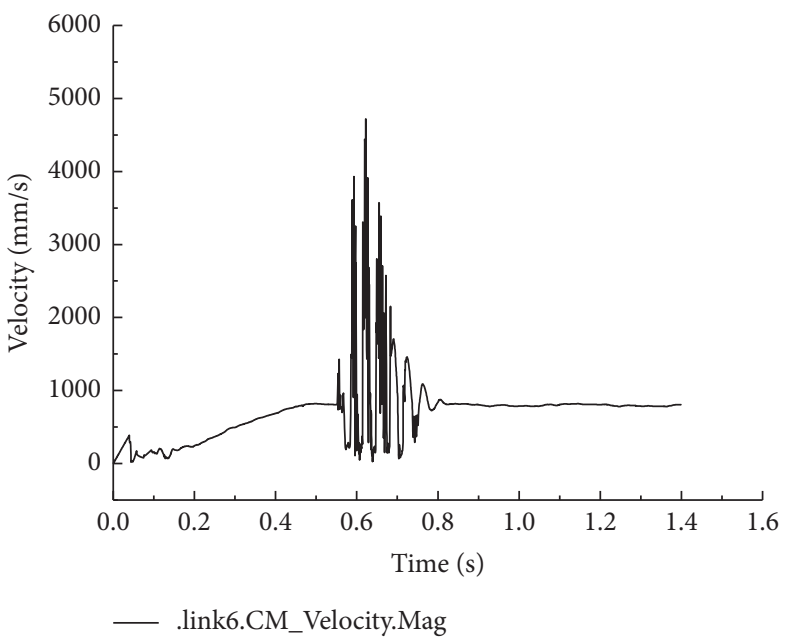

(d)

Figure 7: Link 6 velocity change curve. (a) Velocity in the $X$ direction. (b) Velocity in the $Y$ direction. (c) Velocity in the $Z$ direction. (d) Velocity amplitude.

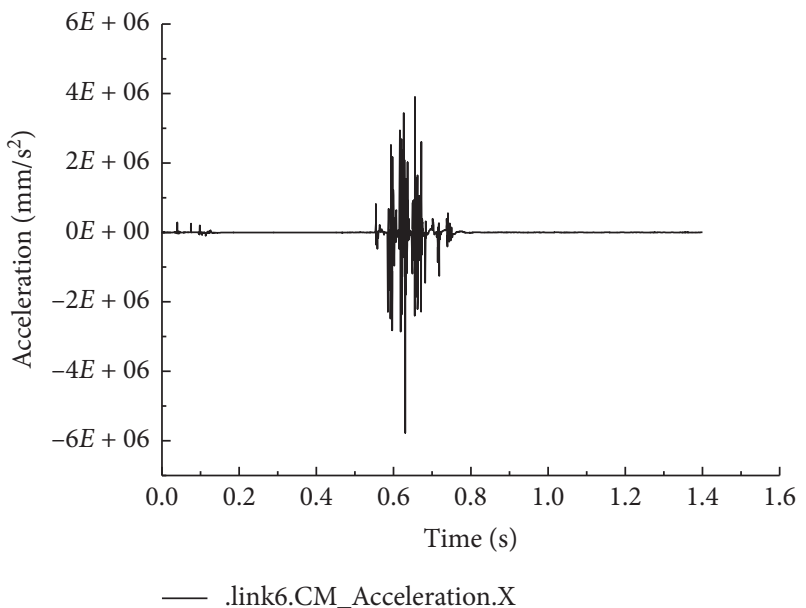

(a)

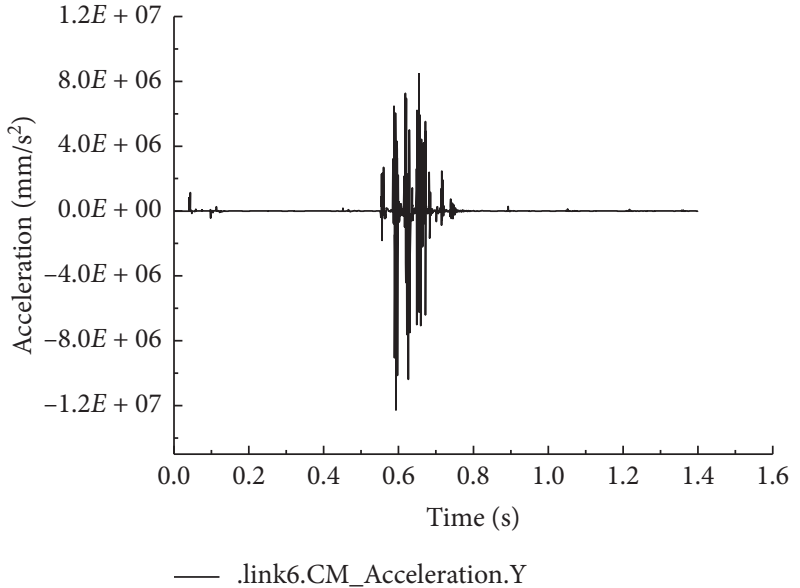

(b)

Figure 8: Continued. 


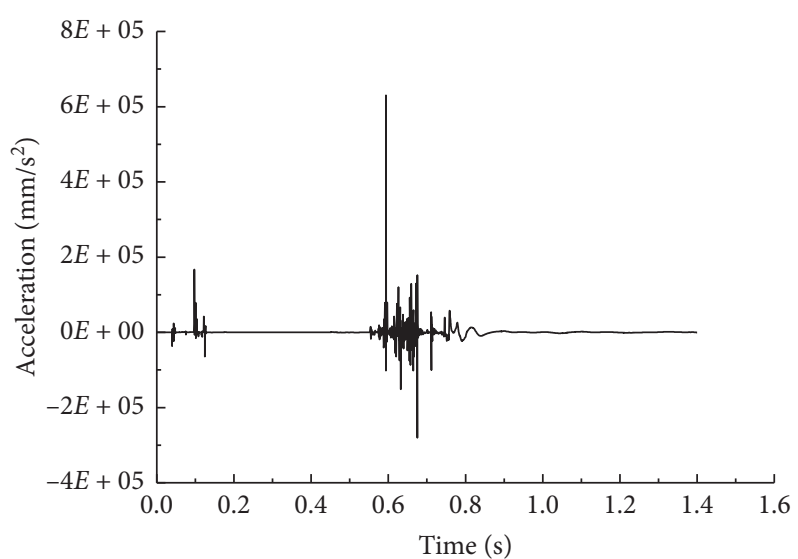

—.link6.CM_Acceleration.Z

(c)

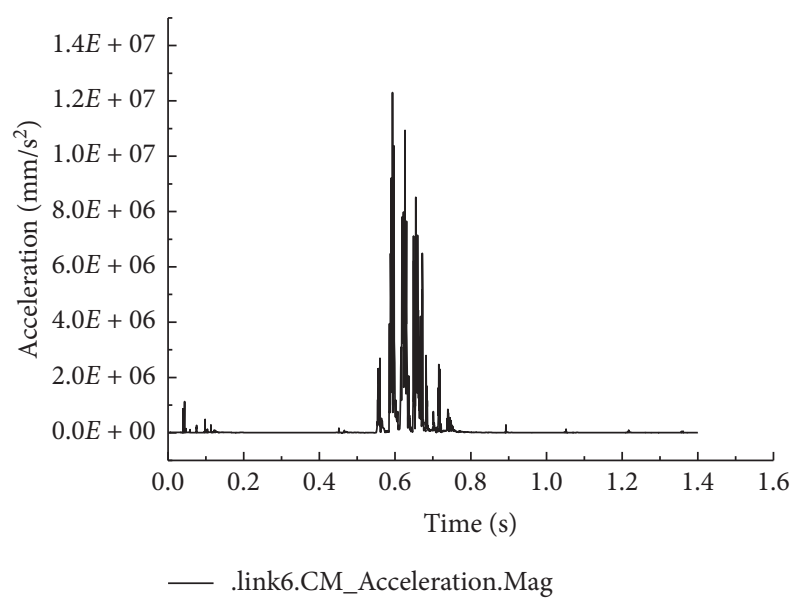

(d)

Figure 8: Link 6 acceleration change curve. (a) Acceleration in the $X$ direction. (b) Acceleration in the $Y$ direction. (c) Acceleration in the $Z$ direction. (d) Acceleration amplitude.

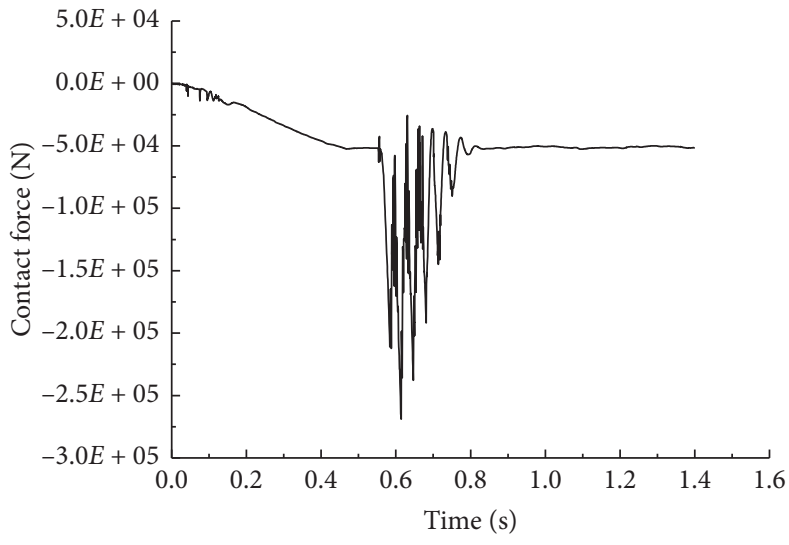

.CONTACT_5_6.Element_Force.X

(a)

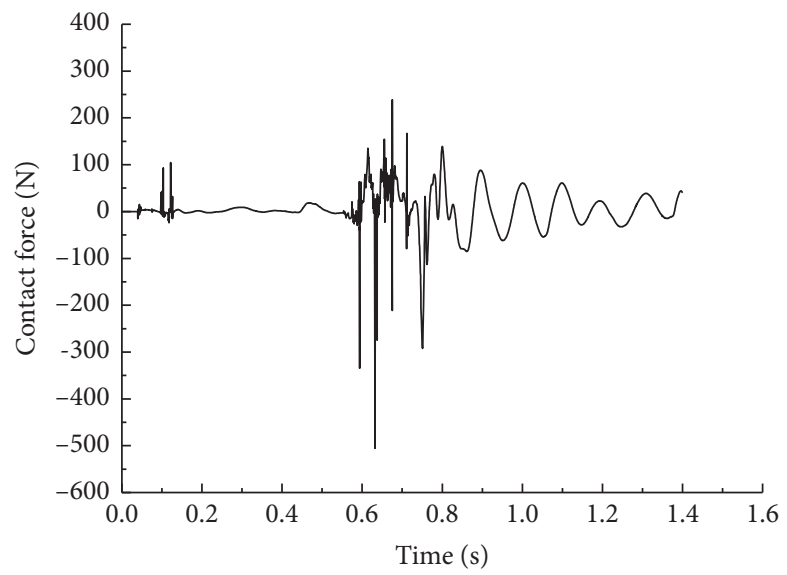

.CONTACT_5_6.Element_Force.Z

(c)

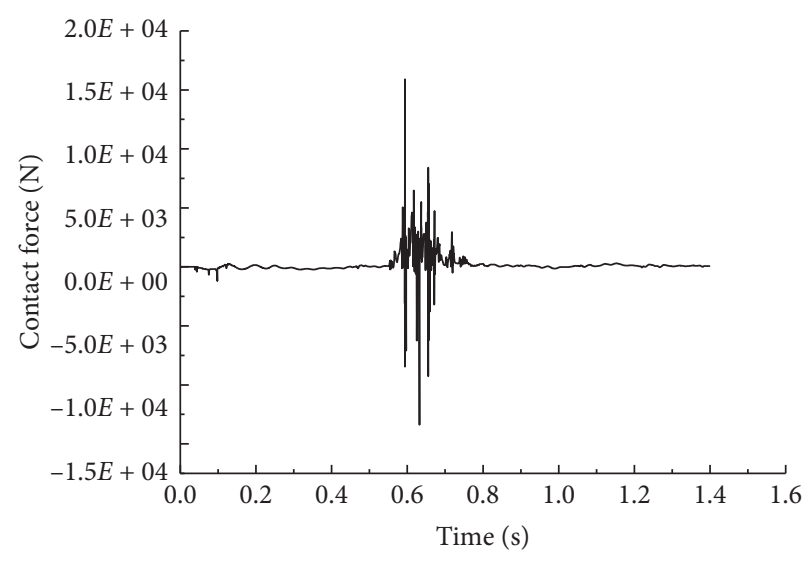

.CONTACT_5_6.Element_Force.Y

(b)

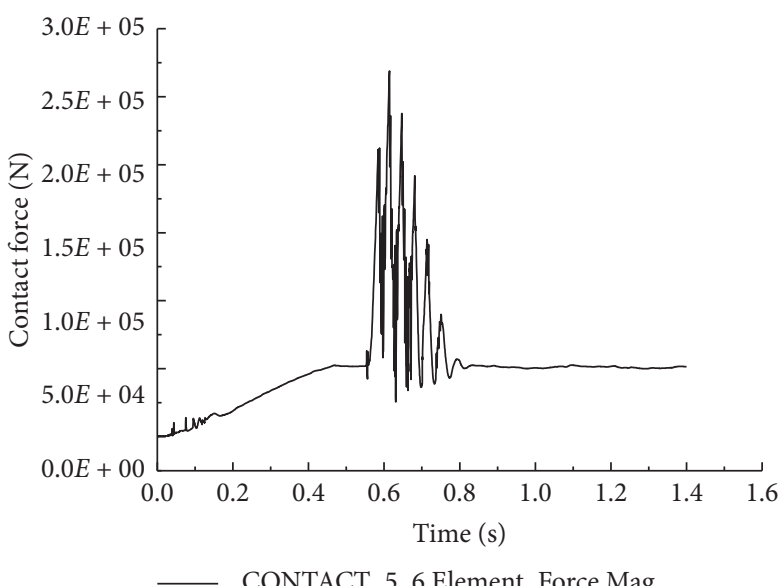

(d)

FIGURE 9: Change of indirect contact force of the chain link under impact load. (a) $X$ component of the contact force. (b) $Y$ component of the contact force. (c) $Z$ component of the contact force. (d) Contact force resultant force. 


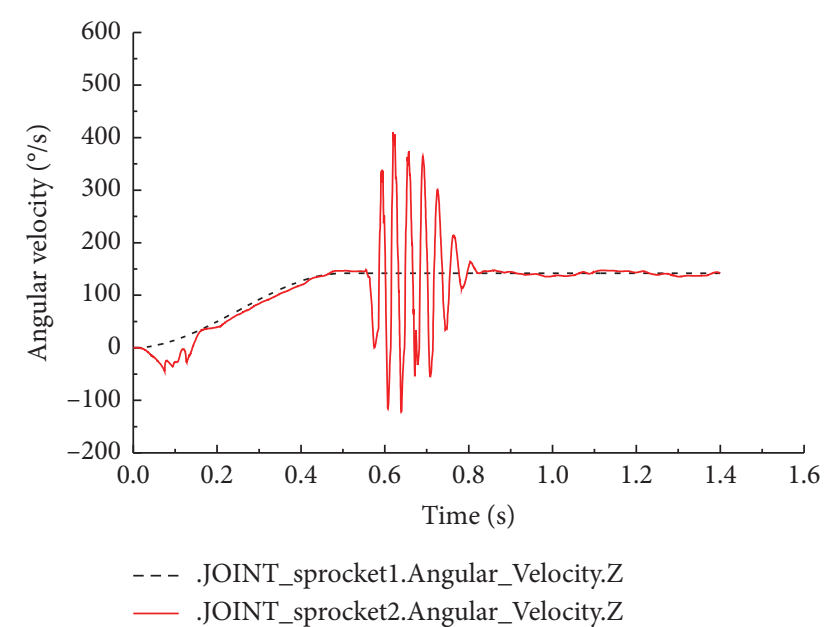

FIgURE 10: Sprocket rotational speed change curve.

3.2. Chain Stuck Condition. The scraper conveyor will be stuck in the process of working. The scraper conveyor is equipped with a friction torque limiter or hydraulic coupler to prevent the motor from burning or other structural parts from being damaged when the chain is stuck. However, the setting value of the friction torque limiter is generally 1.5-2.5 times the rated load, which will cause an impact on the structural components of the scraper conveyor when the chain stuck accident occurs. During the simulation, the friction torque limiter is simulated by adding a friction block at the position of drive sprocket. The equivalent simulation of the friction torque limiter is shown in Figure 11. After the parameters are adjusted several times, the maximum torque provided by the friction torque limiter is set to $116.46 \mathrm{kN} / \mathrm{m}$. The position of the chain stuck is shown in Figure 12. Obstacles are set at the position of the chain, and the chain stuck condition is formed when it contacts with the running scraper.

At $1.68 \mathrm{~s}$, the scraper contacts with the obstacle, and the chain stuck phenomenon occurs. The speed of the chain link at the position of the chain changes. Limited by the computer hardware conditions, the length of the simulation model is not easy to be too long, so the chain position is close to the sprocket, and the chain link in front of the chain position in the simulation cannot avoid the process of meshing with the sprocket. The speed change curve of the flat ring link 13 in front of the chain clamp position is shown in Figure 13. The acceleration curve of link 13 is shown in Figure 14.

The speed change curve of the chain link at the chain of Figure 13 shows that the speed mutation in the running direction ( $X$ direction) is particularly obvious when the chain stuck phenomenon occurs. The curve will basically remain stable after $800 \mathrm{~mm} / \mathrm{s}$ during the previous stable operation to zero in $0.05 \mathrm{~s}$, which is quite different from the speed change of the chain in the longitudinal direction ( $Y$ direction). When the chain is stuck, the chain will produce additional violent vibration in the longitudinal direction, and the amplitude will gradually decrease. In the axial direction of the sprocket ( $Z$ direction), the chain also exhibits slight speed fluctuations, but the amplitude is small, which

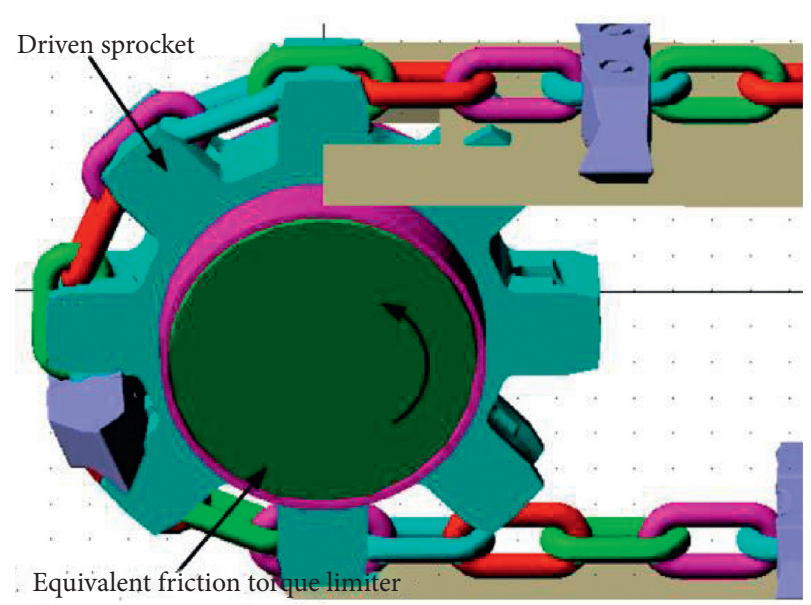

FIgURE 11: Friction torque limiter schematic diagram.

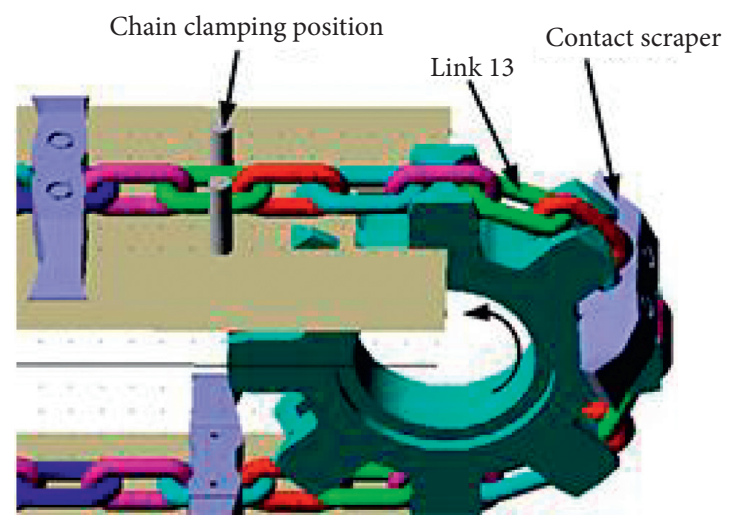

FIgURE 12: Chain stuck position.

has little effect on the change of the speed amplitude of the chain. When the chain is stuck, the speed of the chain will quickly decrease to approximately zero, and the chain link will be accompanied by vibration.

The acceleration change curve of the chain link in Figure 14 shows that when the chain is stuck, the acceleration change of the chain link in the running direction $(X$ direction) is large, reaching $2.65 e 6 \mathrm{~mm} / \mathrm{s}^{2}$. The acceleration in the $Y$ direction fluctuates, the range of variation is approximately $-1.03 \cdot 10^{5}-2.26 \cdot 10^{5} \mathrm{~mm} / \mathrm{s}^{2}$, and the maximum value of acceleration amplitude is $1.56 \cdot 10^{7} \mathrm{~mm} / \mathrm{s}^{2}$, thereby indicating that the chain link is greatly impacted when the chain is stuck. The change curve of the contact force between links 12 and 13 is obtained to study the stress of the link at this time (Figure 15).

Figure 15 shows that when the chain is stuck, the indirect contact force of the chain link rapidly increases, and the change is obvious in the running direction ( $X$ direction). In the period of $0.04-0.05 \mathrm{~s}$, the contact force changes from $5 \cdot 10^{4} \mathrm{~N}$ to $-3 \cdot 6 \cdot 10^{5} \mathrm{~N}$. In the $Y$ direction, fluctuations occur in the contact force between the links, which may be related to the longitudinal velocity fluctuations of the chain links. The change curve of the contact force demonstrates that the indirect contact force of chain link is approximately $5 \cdot 10^{4} \mathrm{~N}$ when smoothly running. 


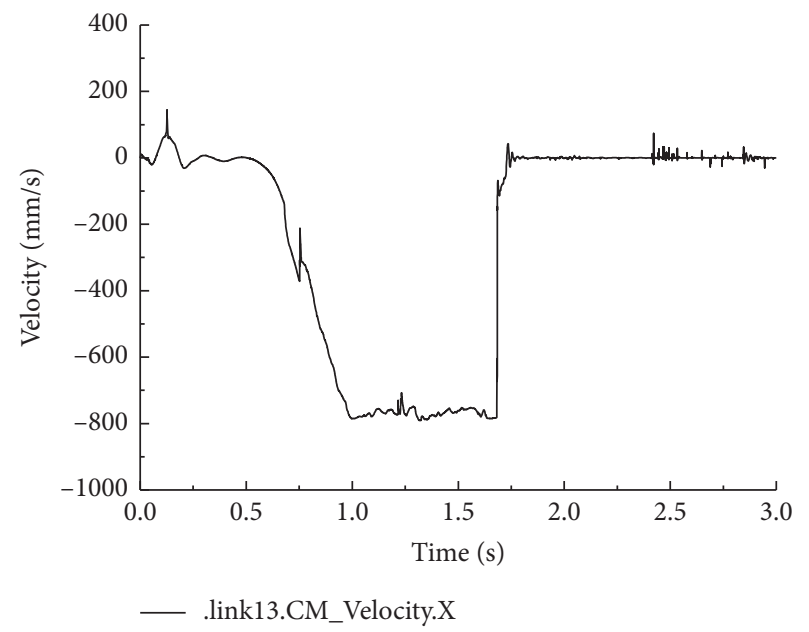

(a)

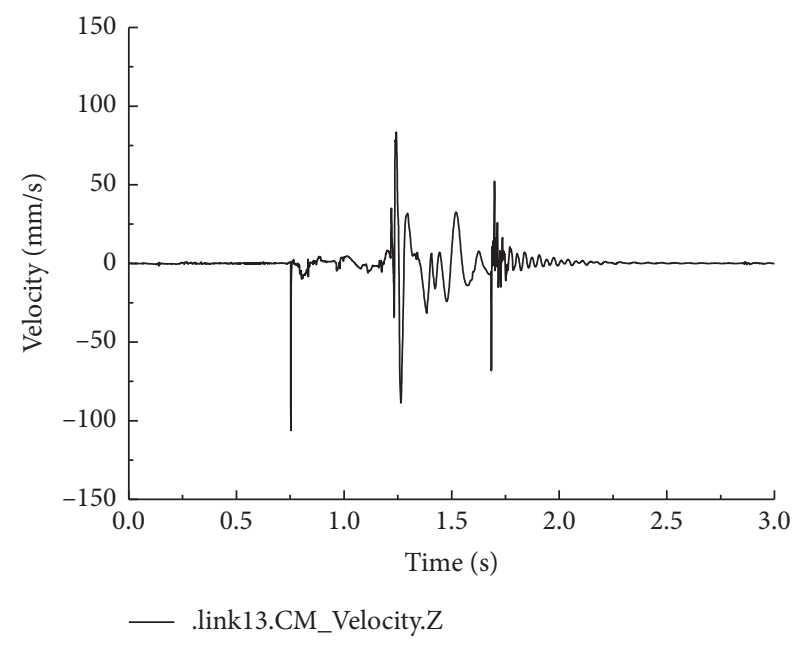

(c)

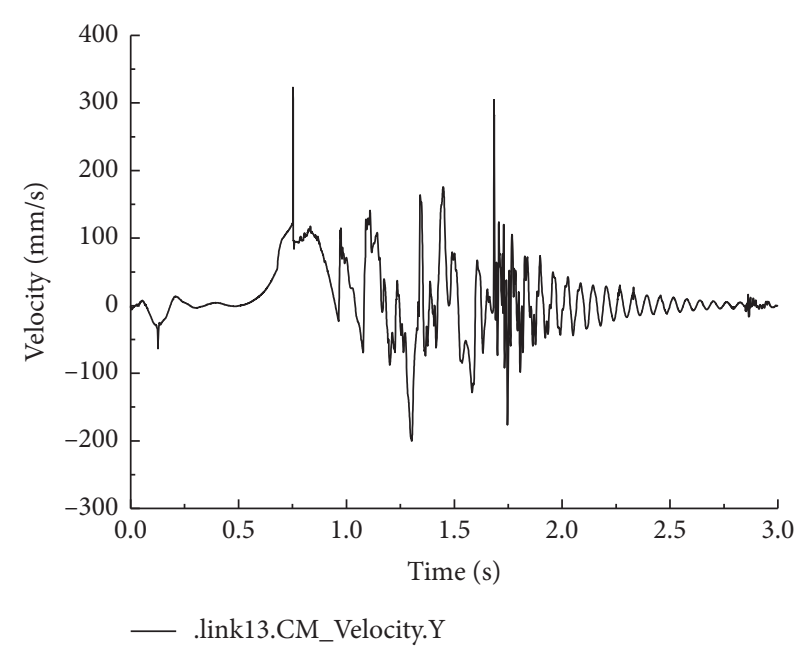

(b)

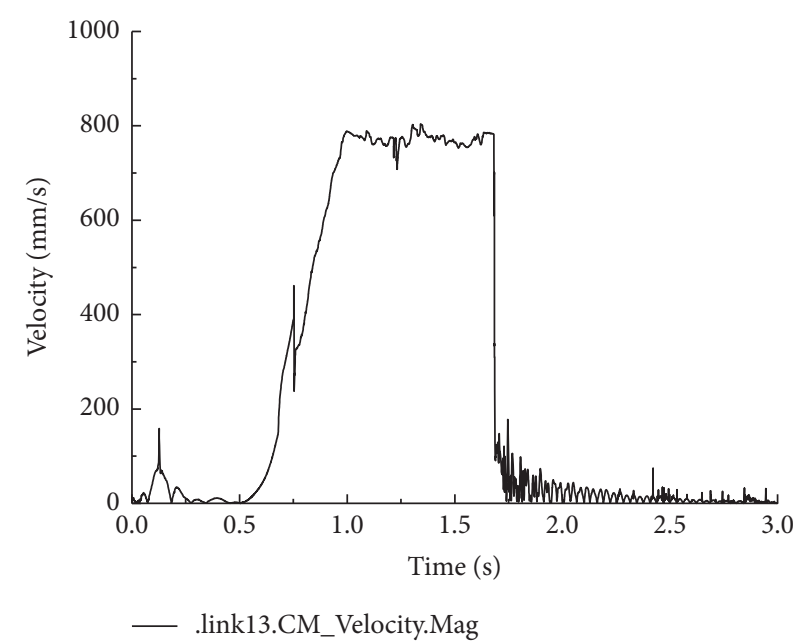

(d)

FIGURE 13: Link acceleration change curve at the chain blocked position. (a) Velocity in the $X$ direction. (b) Velocity in the $Y$ direction. (c) Velocity in the $Z$ direction. (d) Velocity amplitude.

When the chain is stuck, the indirect contact force of the chain link instantaneously increases, thereby reaching the maximum pull force provided by the friction torque limiter, which is 7.2 times higher than that when the chain is smoothly running. This finding shows that when the chain transmission system is stuck, the chain link will be greatly impacted and easily damaged. When the chain is stuck, the motor drives the friction torque limiter to slip, which has a great impact on the running speed of the chain drive system. The speed curve of the sprocket is shown in Figure 16.

The change curve of the sprocket wheel speed (Figure 16) shows that the friction torque regulator starts to exert torque on the drive sprocket after $0.5 \mathrm{~s}$. The sprocket smoothly runs according to the boundary condition of $141.7^{\circ} / \mathrm{s}$ after $1 \mathrm{~s}$. The driving sprocket sprocket_1 and driven sprocket sprocket_2 have basically the same speed change trend. When the chain is stuck, the speed of the sprocket rapidly decreases to zero. However, the speed fluctuation of the driving sprocket is slightly greater than that of the driven sprocket. The speed of the sprocket suddenly changes, and the chain socket of the sprocket is greatly impacted, thereby causing the deformation and damage of the chain socket.

3.3. Broken Chain Condition. The broken chain condition is realized by setting the simulation script in ADAMS. The connection contact between links 1 and 2 fails when the time of chain breaking is reached; thus, the fatigue fracture of chain link can be simulated by setting the sensors. The speed change curve of the link at the broken link when the link breaks is shown in Figure 17. The connection between links 1 and 2 fails after $1.13 \mathrm{~s}$. After fatigue fracture of chain link, link 1 at the side near the driving sprocket no longer bears load resistance, and its running speed increases to approximately $-1533 \mathrm{~mm} / \mathrm{s}$. The speed of link 2 on the side of the driven sprocket rapidly decreases to near zero. The negative velocity in the $Y$ direction is large because of the absence of contact between the chain link and the middle groove in the model. The link freely falls under the action of gravity after the chain is broken. 


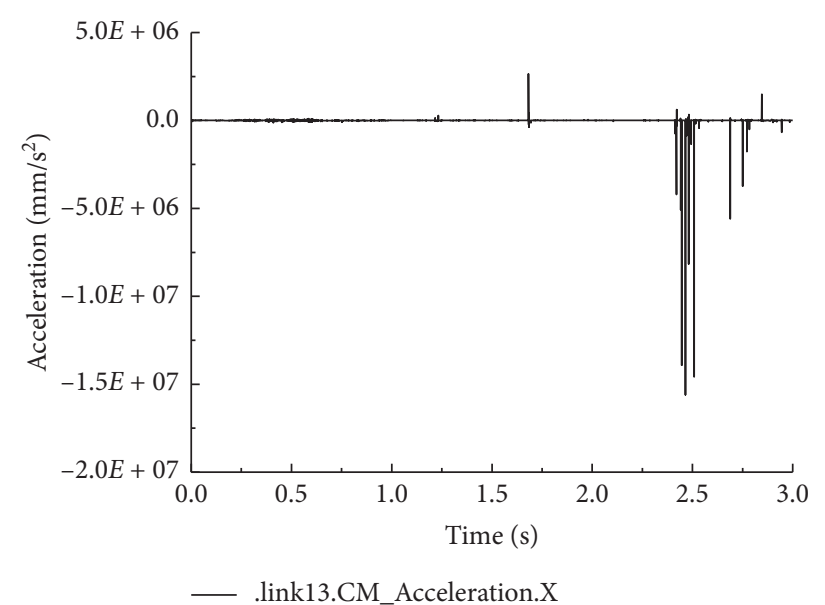

(a)

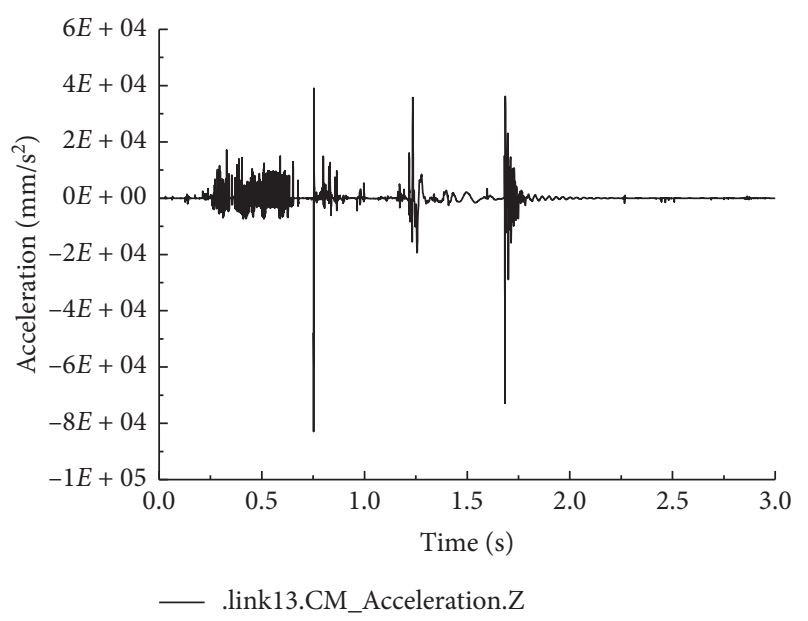

(c)

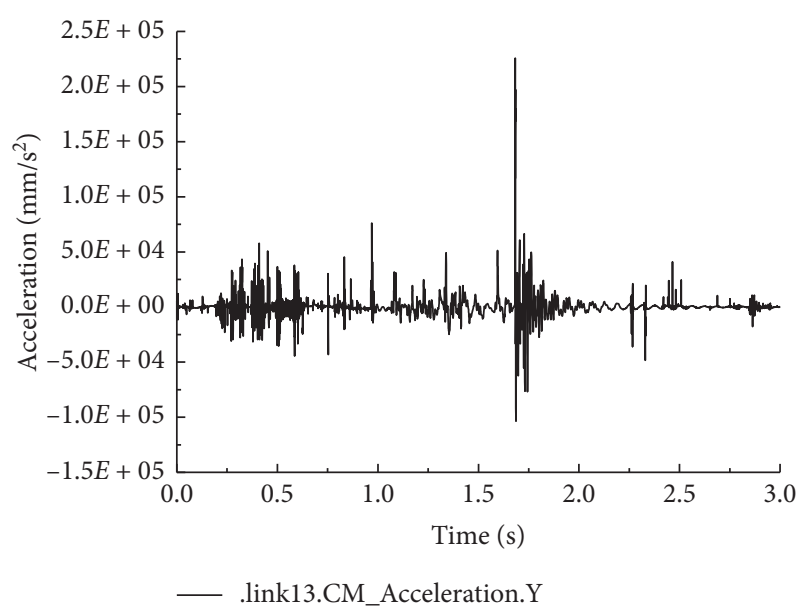

(b)

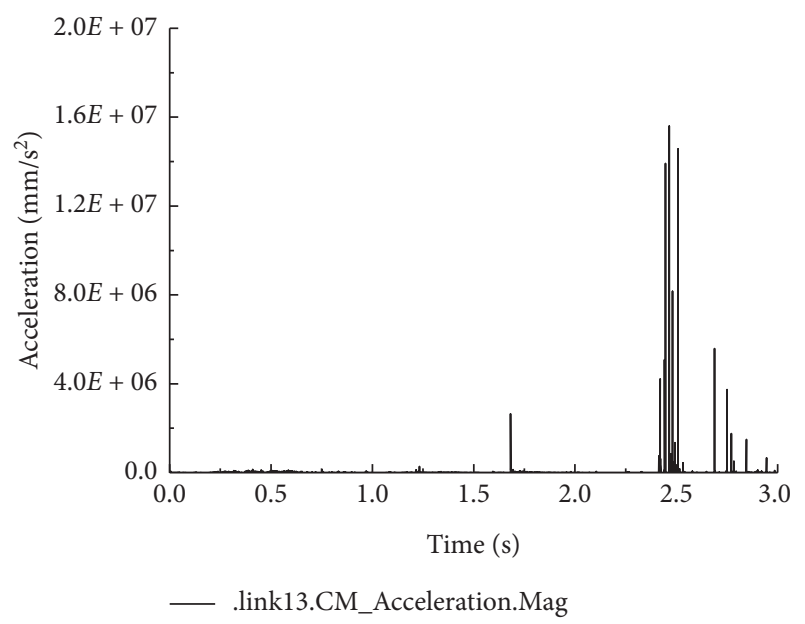

(d)

Figure 14: Link acceleration change curve at the chain blocked position. (a) Acceleration in the $X$ direction. (b) Acceleration in the $Y$ direction. (c) Acceleration in the $Z$ direction. (d) Acceleration amplitude.

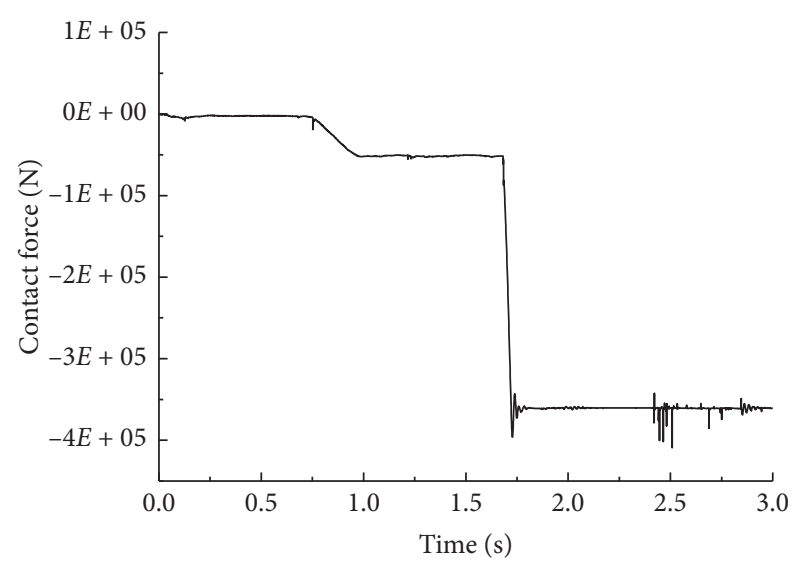

.CONTACT_12_13.Element_Force.X

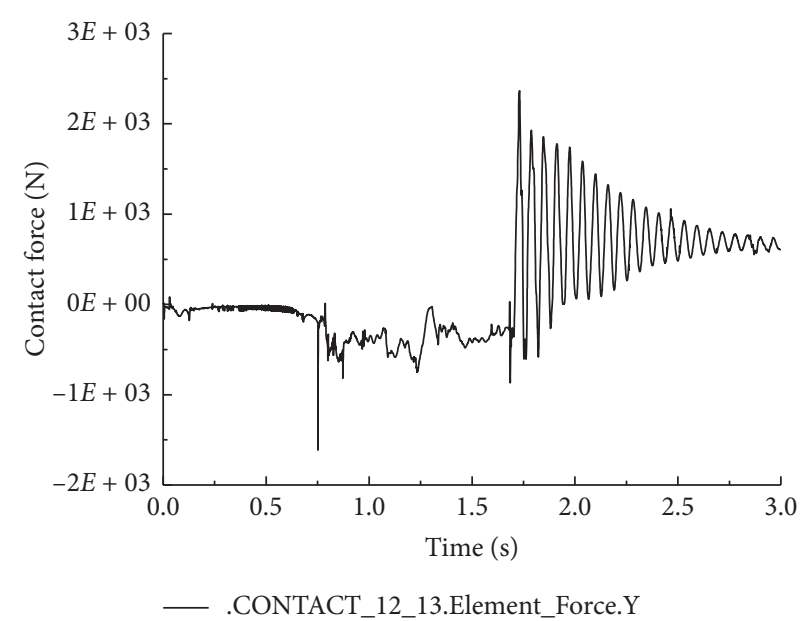

(b)

FIgURE 15: Continued. 


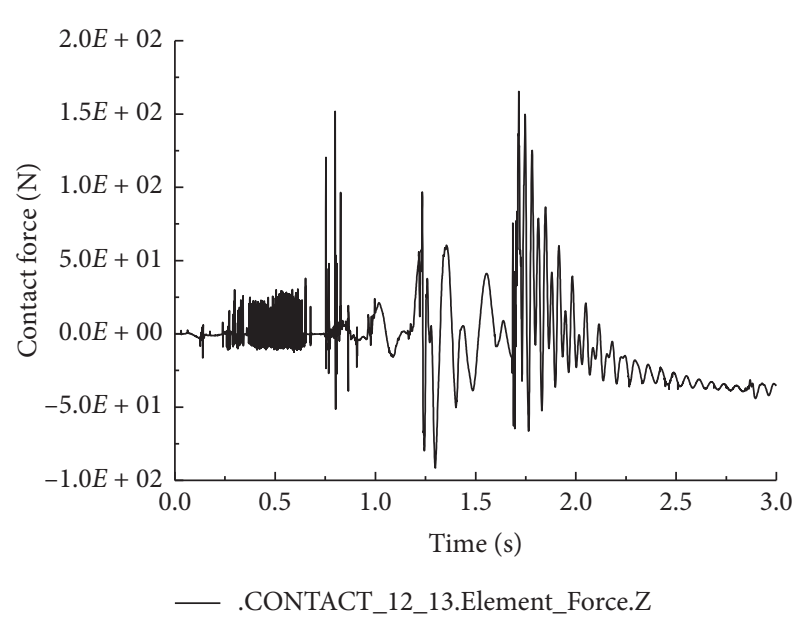

(c)

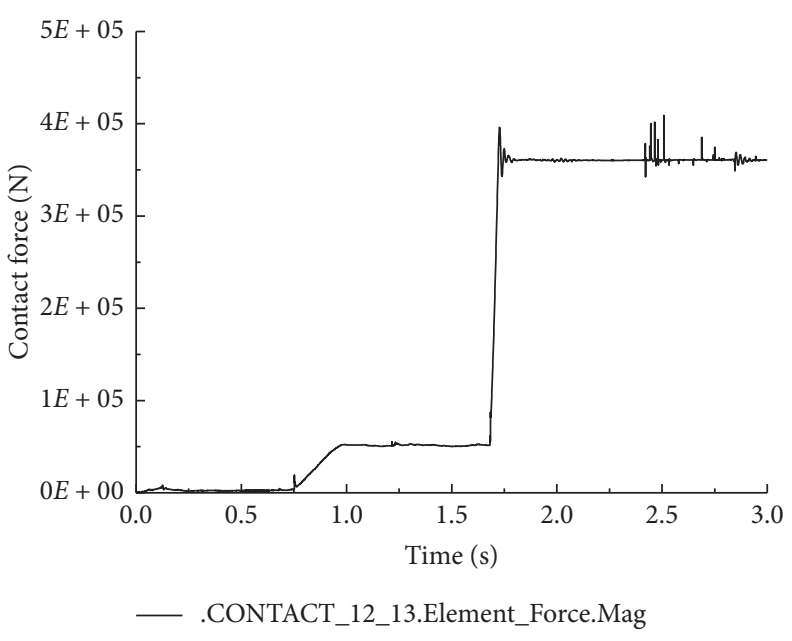

(d)

FIGURE 15: Contact force change between the links at the chain blocked position. (a) Contact force in the $X$ direction. (b) Contact force in the $Y$ direction. (c) Contact force in the $Z$ direction. (d) Contact force amplitude.

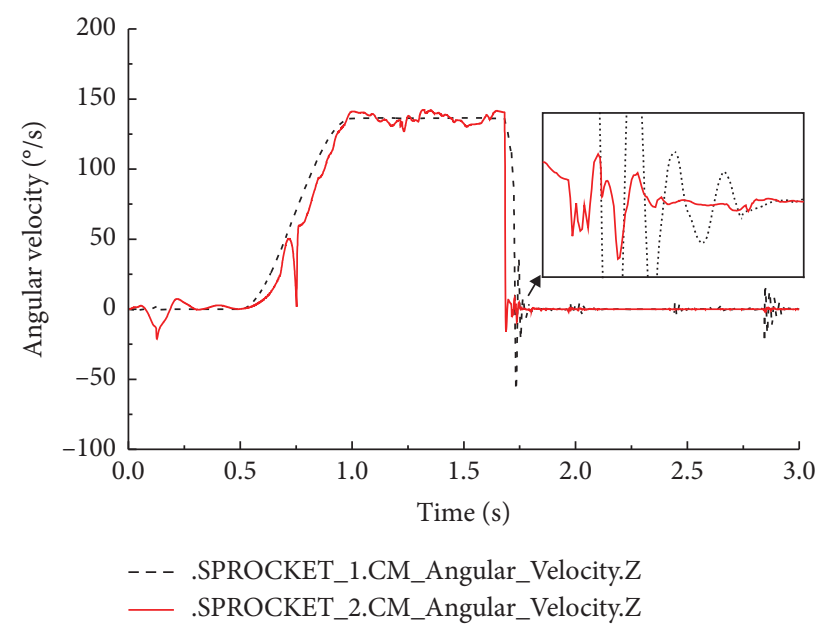

FIGURE 16: Sprocket rotational speed change curve after the chain is blocked.

The change curve of the link acceleration at the point where the link is broken when fatigue fracture occurs on the chain link is shown in Figure 18. When the link is broken, the acceleration of the link has a huge mutation, mainly in the running direction, and the maximum value is $1.8 \cdot 10^{7} \mathrm{~mm} / \mathrm{s}^{2}$. A large acceleration change also occurred in the $Y$ direction, thereby indicating that the chain drive system of scraper conveyor will be greatly impacted after the chain link fatigue fracture.

The change curve of the indirect contact force at the broken link when fatigue fracture occurs is shown in
Figure 19. The change curve of the contact force in the $X$ direction demonstrates that the contact force between the chain links is basically stable at approximately $5 \cdot 10^{4} \mathrm{~N}$ during a smooth operation. The contact force in the $Y$ direction is small. When the time reaches $1.13 \mathrm{~s}$, the connection contact between links 1 and 2 fails, and the contact forces in all directions become zero, thereby indicating that the action of sensor definition in the simulation script starts to execute. This finding is consistent with the established simulation conditions and conforms to the change characteristics of contact force when the chain link is fatigued and fractured. 

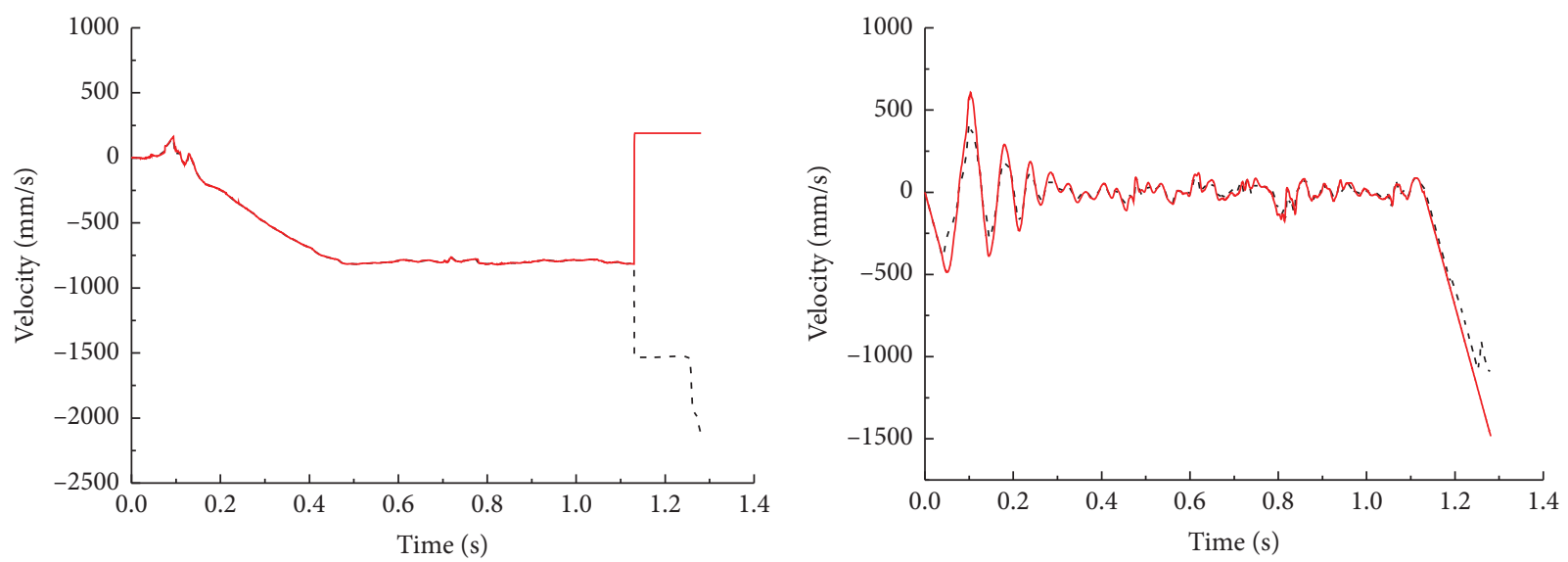

-- - link1.CM_Velocity.X
— link2.CM_Velocity.X

(a)

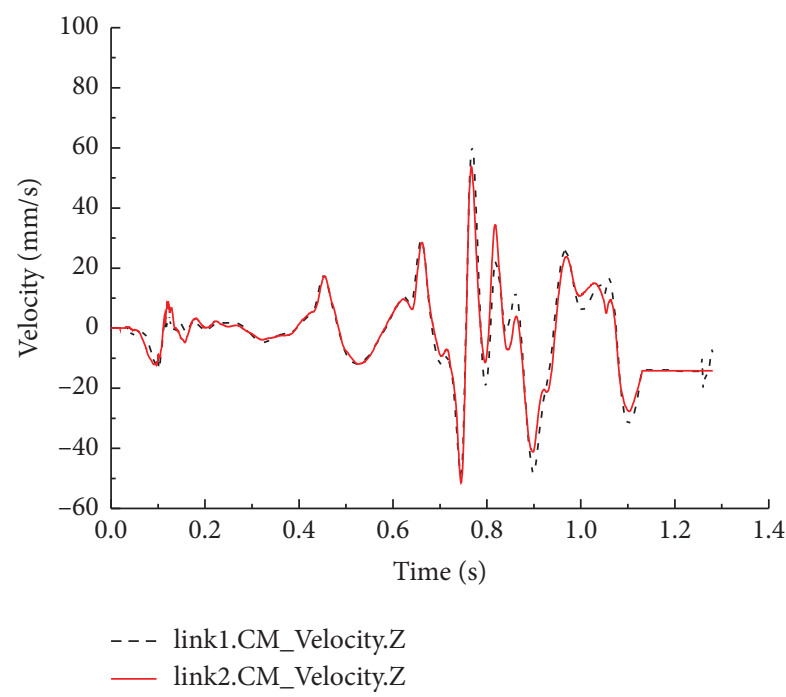

(c)
- - - link1.CM_Velocity.Y

— link2.CM_Velocity.Y

(b)

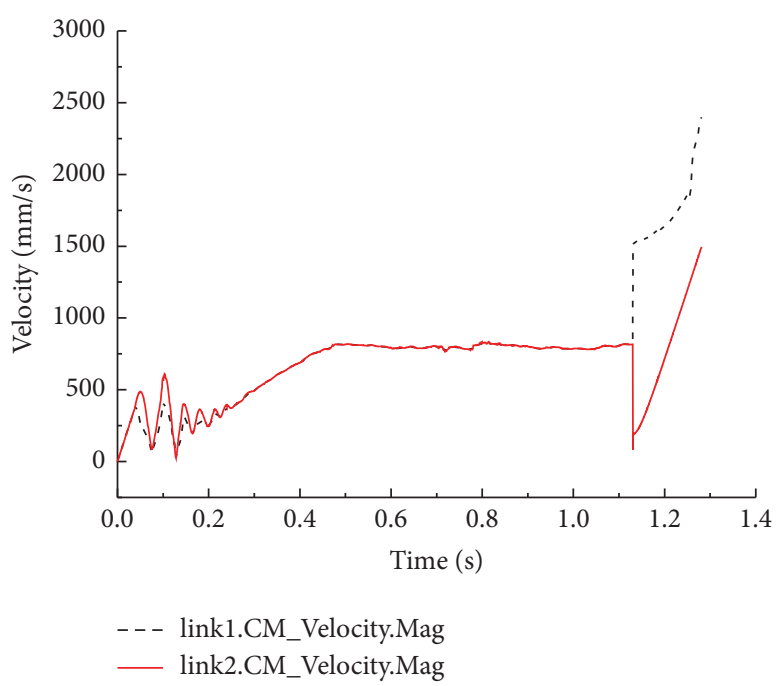

(d)

FIGURE 17: Link velocity change curve at the chain rupture position. (a) Velocity in the $X$ direction. (b) Velocity in the $Y$ direction. (c) Velocity in the $Z$ direction. (d) Velocity amplitude.

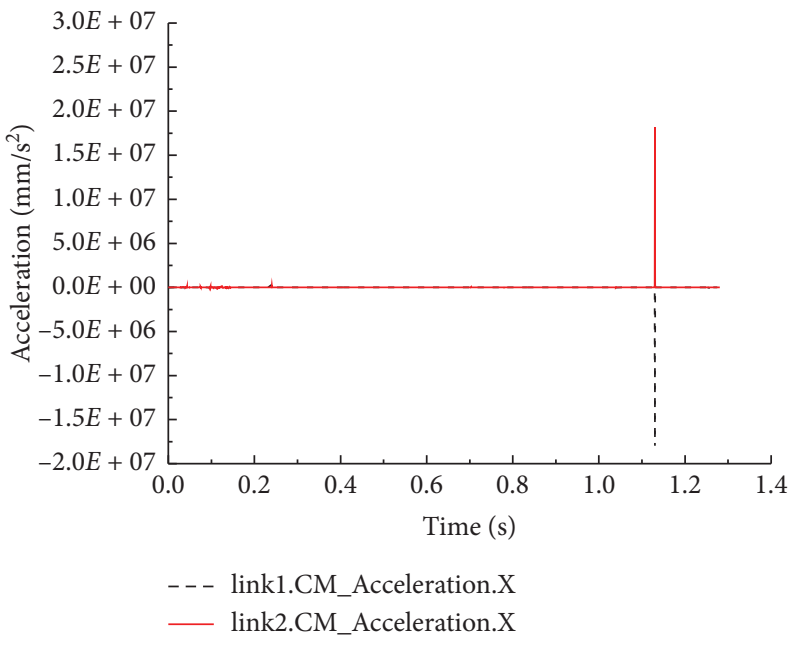

(a)

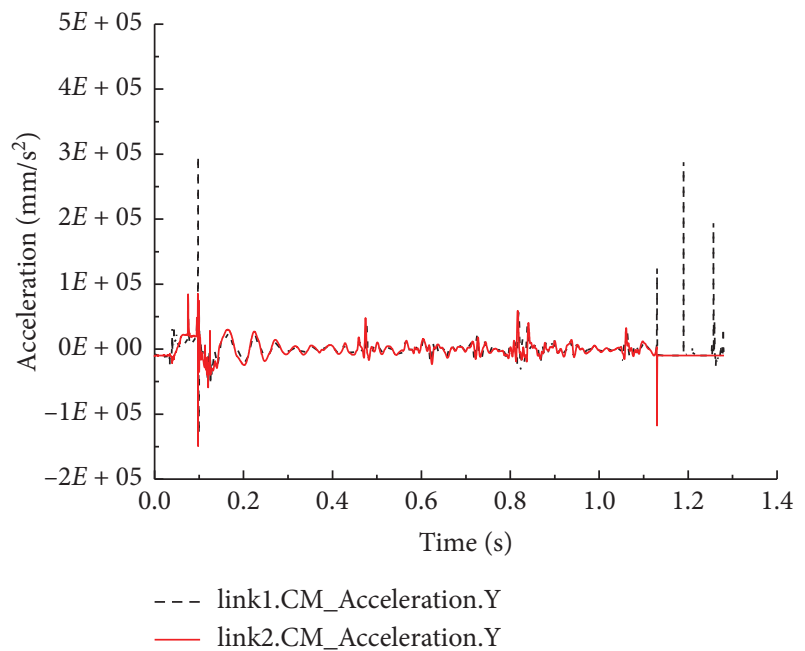

(b)

Figure 18: Continued. 


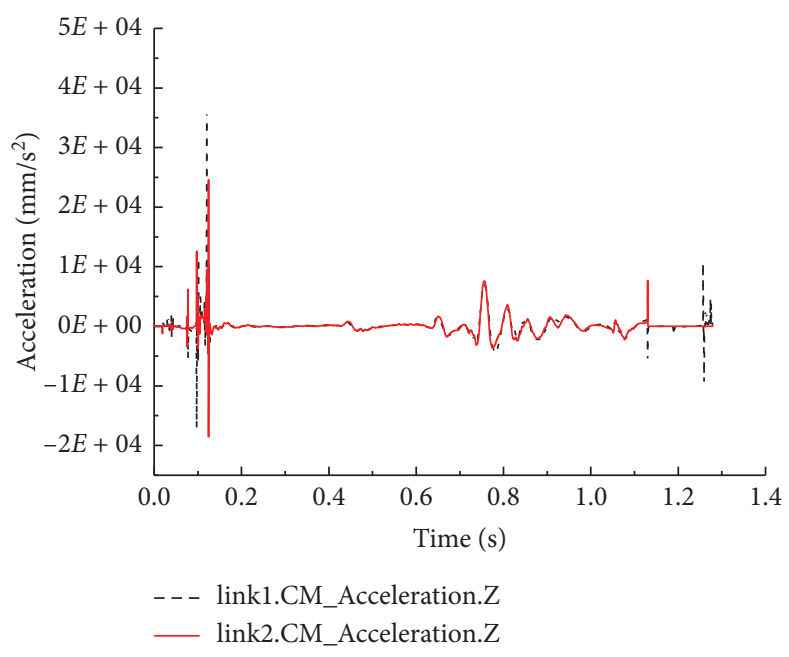

(c)

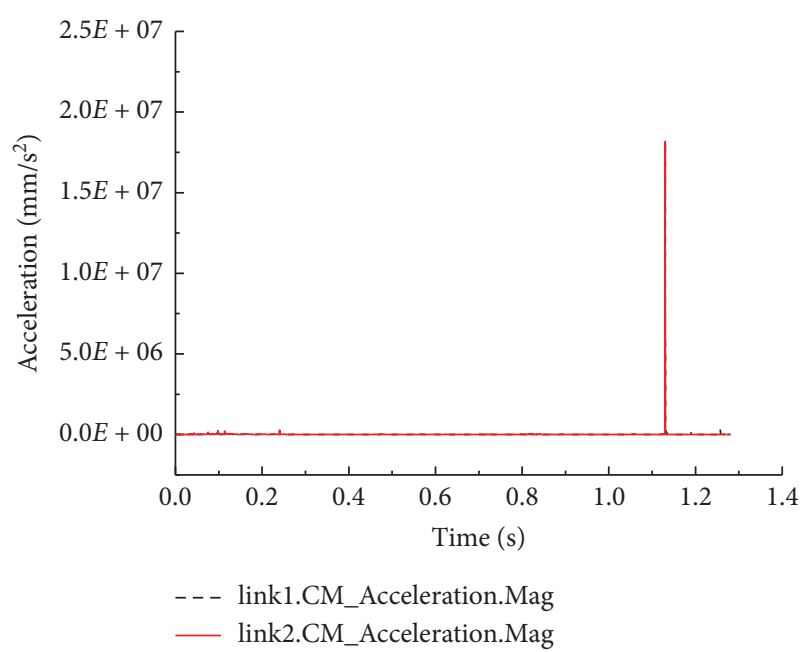

(d)

FIgURE 18: Link acceleration change curve at the chain rupture position. (a) Acceleration in the $X$ direction. (b) Acceleration in the $Y$ direction. (c) Acceleration in the $Z$ direction. (d) Acceleration amplitude.

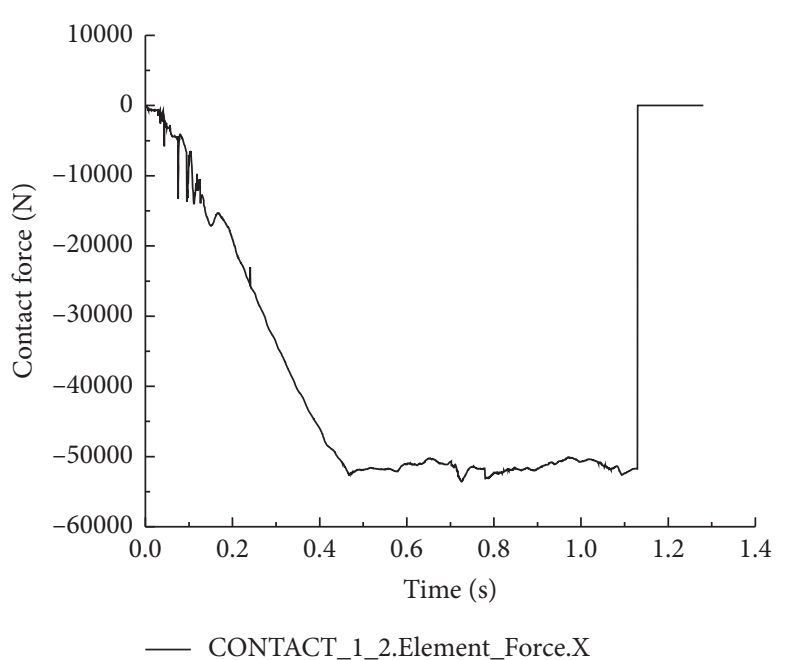

(a)

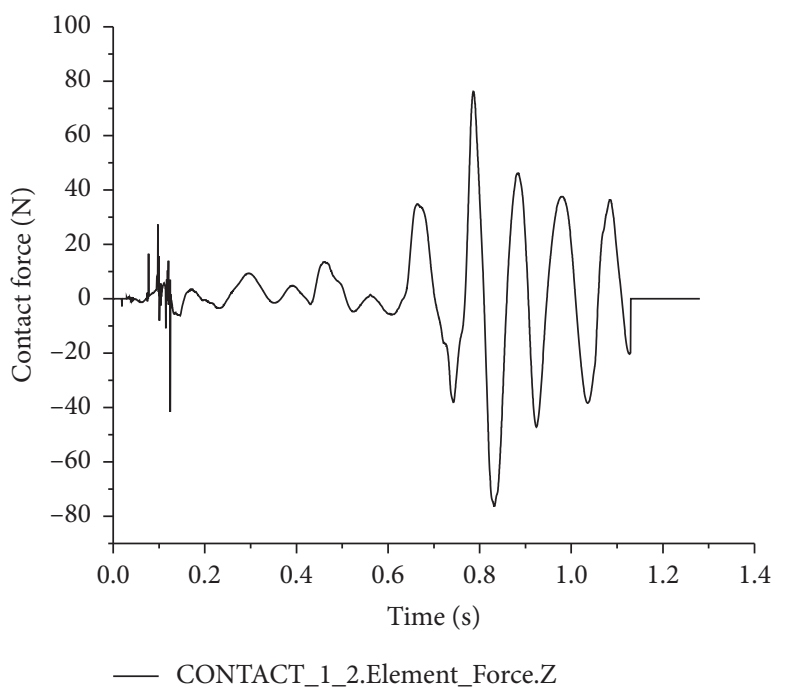

(c)

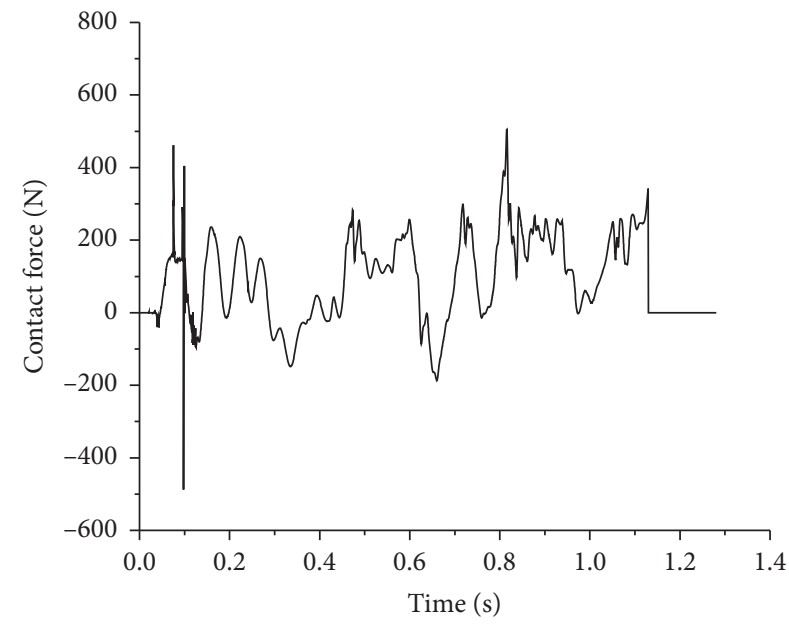

CONTACT_1_2.Element_Force.Y

(b)

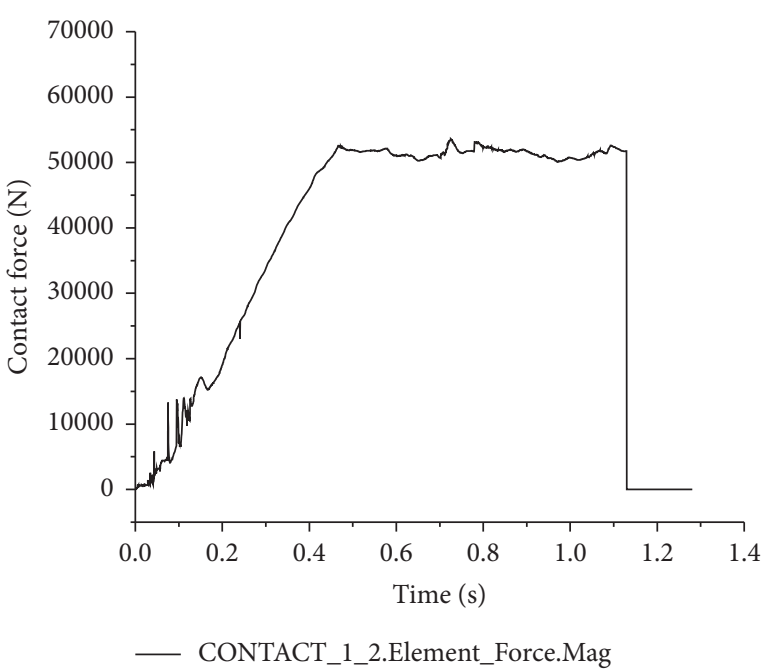

(d)

FIGURE 19: Contact force change between links at the chain rupture position. (a) Contact force in the $X$ direction. (b) Contact force in the $Y$ direction. (c) Contact force in the $Z$ direction. (d) Contact force amplitude. 


\section{Conclusions}

In this study, a virtual prototype model of the chain drive system of the scraper conveyor was established on the basis of the multibody dynamic theory. A test bench for the dynamic characteristics of the chain drive system was created to verify the accuracy of the simulation. This study focused on the impact of load on the operation of the chain drive system and simulated the abnormal working conditions, such as the stuck chain and broken chain of the scraper conveyor. The following conclusions are drawn on the basis of the simulation analytical results:

(1) The experimental and simulated sprocket speed data and the theoretical calculation values have small differences. The simulation results are in line with the actual working conditions, and the credibility is high. In the acceleration test of the scraper operation, the simulation results are basically consistent with the change trend of the test results. The simulation results are in good agreement with the experimental results, and the simulation data have high credibility.

(2) When the chain transmission system is subjected to an impact load, the speed and acceleration of the chainring in the $Y$ direction drastically change. The peak speed is $4340 \mathrm{~mm} / \mathrm{s}$, and the peak acceleration is $1.23 \cdot 10^{7} \mathrm{~mm} / \mathrm{s}^{2}$. The peak acceleration of the chain link in the $Y$ direction reaches twice the $X$ direction. In the running direction, the speed fluctuation is obvious, and the peak value can reach $4720 \mathrm{~mm} / \mathrm{s}$, thereby indicating that the chain link vibrates back and forth. The contact force between the chain links has dramatically increased, reaching a maximum of $2.75 \cdot 10^{5} \mathrm{~N}$, which is 5.4 times higher than when smoothly running. The impact load affects the stability of the chain drive system and changes the meshing contact force of the sprocket assembly.

(3) When the chain is stuck, the chain speed will quickly drop to zero, and the longitudinal ( $Y$ direction) speed greatly changes, thereby indicating that the longitudinal vibration occurs. The acceleration in the $Y$ direction fluctuates, and the maximum value is $1.56 \cdot 10^{7} \mathrm{~mm} / \mathrm{s}^{2}$, thereby indicating that the chain link is greatly impacted. The contact force between the chainrings instantaneously increases, which is 7.2 times higher than that during a smooth operation. This finding shows that the chainring will be subjected to a huge impact when the chain transmission system is stuck, which can easily cause damage.

(4) When a broken chain fault occurs, the acceleration of the chain link is greatly abruptly changed, which is mainly reflected in the running direction, and it can reach up to $1.8 \cdot 10^{7} \mathrm{~mm} / \mathrm{s}^{2}$. This situation indicates that the fatigue of the chain link will have a great impact on the chain transmission system of the scraper conveyor. The chain break accident will seriously affect the safety of production. In actual production, a reasonable maintenance time can be easily arranged to prevent fatigue damage of parts.

\section{Data Availability}

The results of simulations and experiments are shown in the figures of the paper and the data used to support the findings of this study are included within the paper.

\section{Conflicts of Interest}

The authors declare that there are no conflicts of interest regarding the publication of this paper.

\section{Acknowledgments}

This work was supported by the Shandong Provincial Natural Science Foundation (Grant no. ZR2019BEE066); Applied Basic Research Project of Qingdao (Grant no. 196-2-68-cg); Shandong Provincial Key Research and Development Project (Grant no. 2019SDZY01); Project of Shaanxi Key Laboratory of Mine Electromechanical Equipment Intelligent Monitoring (Xi'an University of Science and Technology) (Grant no. SKL-MEEIM201906); and Project of Shandong Province Higher Educational Young Innovative Talent Introduction and Cultivation Team (Performance Enhancement of Deep Coal Mining Equipment). The authors would also acknowledge the Shandong Provincial Key Laboratory of Mining Machinery Engineering for providing the experimental venue.

\section{References}

[1] K. Szewerda, J. Świder, and K. Herbuś, “Analysis of impact of longitudinal inclination of a chain conveyor on dynamical phenomena during operation," MATEC Web of Conferences, vol. 94, 2017.

[2] H. Ding, Y. Liu, and J. Liu, "Volumetric tooth wear measurement of scraper conveyor sprocket using shape from focus-based method," Applied Sciences, vol. 9, no. 6, p. 1084, 2019.

[3] O. Stoicuta, T. Pana, and C. Mandrescu, "The control system analysis of the coal flow on the scrapers conveyor in a longwall mining system," in Proceedings of the 2016 International Conference on Applied and Theoretical Electricity (ICATE), Craiova, Romania, October 2016.

[4] Y. Hu, Q. Zeng, S. Jiang, P. Yu, and Z. Yang, "Dynamic analysis of chain drive system for scraper conveyor based on amesim," IOP Conference Series: Materials Science and Engineering, vol. 452, 2018.

[5] L. Li, H. Cui, Z. Lian, and Q. Wang, "Modeling and optimization of soft start-up for hydroviscous drive applied to scraper conveyor," Mathematical Problems in Engineering, vol. 2019, 13 pages, 2019.

[6] Z. Shi and Z. Zhu, "Case Study: wear analysis of the middle plate of a heavy-load scraper conveyor chute under a range of operating conditions," Wear, vol. 380-381, pp. 36-41, 2017.

[7] J. Xie, Z. Yang, X. Wang, S. Wang, and Q. Zhang, "A joint positioning and attitude solving method for shearer and 
scraper conveyor under complex conditions," Mathematical Problems in Engineering, vol. 2017, 14 pages, 2017.

[8] X. Zhang, W. Li, Z. Zhu, S. Yang, and F. Jiang, "Fault detection for the scraper chain based on vibration analysis using the adaptive optimal kernel time-frequency representation," Shock and Vibration, vol. 2019, 14 pages, 2019.

[9] X. Wang, B. Li, S. Wang, Z. Yang, and L. Cai, "The transporting efficiency and mechanical behavior analysis of scraper conveyor," Proceedings of the Institution of Mechanical Engineers, Part C: Journal of Mechanical Engineering Science, vol. 232, no. 18, pp. 3315-3324, 2017.

[10] S. B. Jiang, Q. L. Zeng, G. Wang, K. D. Gao, Q. Y. Wang, and K. Hidenori, "Contact analysis of chain drive in scraper conveyor based on dynamic meshing properties," International Journal of Simulation Modelling, vol. 17, no. 1, pp. 81-91, 2018.

[11] Y. Wang and S. Wang, "Coordinated speed planning strategy of scraper conveyor and shearer based on scraper conveyor loads analysis," IOP Conference Series: Earth and Environmental Science, vol. 267, 2019.

[12] D. Zhang, J. Mao, and Z. Liu, "Dynamics simulation and experiment on the starting and braking of scraper conveyor," Journal of China Coal Society, vol. 41, no. 2, pp. 513-521, 2016.

[13] H. Z. Jiao, Z. J. Yang, and S. P. Wang, "Contact dynamics simulation analysis for sprocket transmission system of scraper conveyor," Journal of China Coal Society, vol. 37, pp. 494-498, 2012.

[14] J. Yang, S. Fu, and D. Wang, "Dynamic simulation of startupcharacteristics of scraper conveyor based AMEsim," in Proceedings of the 2015 IEEE International Conference on Mechatronics and Automation (ICMA), Beijing, China, August 2015.

[15] D. Wang, J. Zhang, Z. Zhu, S. Gang, and L. Xiang, "Crack initiation characteristics of ring chain of heavy-duty scraper conveyor under time-varying loads," Advances in Mechanical Engineering, vol. 11, no. 9, 2019.

[16] C. Xie, Z. Liu, J. Mao et al., "Analysis of torsional vibration characteristics of scraper conveyor on chain blocked condition," Journal of China Coal Society, vol. 43, no. 8, pp. 2348-2354, 2018.

[17] S. B. Jiang, X. Zhang, K. D. Gao, J. Gao, Q. Y. Wang, and K. Hidenori, "Multi-body dynamics and vibration analysis of chain assembly in armoured face conveyor," International Journal of Simulation Modelling, vol. 16, no. 3, pp. 458-470, 2017.

[18] R. Xia, B. Li, X. Wang, Z. Yang, and L. Liu, "Screening the main factors affecting the wear of the scraper conveyor chute using the plackett-burman method," Mathematical Problems in Engineering, vol. 2019, 11 pages, 2019.

[19] J. Li and S. Liang, "Friction and wear of the middle trough in scraper conveyors," Industrial Lubrication and Tribology, vol. 70, no. 6, pp. 1072-1077, 2018.

[20] R. Xia, X. Wang, B. Li, X. Wei, and Z. Yang, "Discrete element method- (DEM-) based study on the wear mechanism and wear regularity in scraper conveyor chutes," Mathematical Problems in Engineering, vol. 2019, 12 pages, 2019.

[21] B. Li, X. Wang, R. Xia, Z. Yang, Y. Liu, and T. Li, "Research on the bionic design of the middle trough of a scraper conveyor based on the finite element method," Proceedings of the Institution of Mechanical Engineers, Part C: Journal of Mechanical Engineering Science, vol. 233, no. 9, pp. 3286-3301, 2018.

[22] R. Xia, X. Wang, B. Li, X. Wei, and Z. Yang, "The prediction of wear on a scraper conveyor chute affected by different factors based on the discrete element method," Proceedings of the Institution of Mechanical Engineers, Part C: Journal of Mechanical Engineering Science, vol. 233, no. 17, p. 6229, 2019.

[23] J. Li, Z. Zhu, Y. Peng, and G. Shen, "Microstructure and wear characteristics of novel Fe-Ni matrix wear-resistant composites on the middle chute of the scraper conveyor," Journal of Materials Research and Technology, vol. 9, no. 1, p. 935, 2020. 